TI 2012-108/VIII

Tinbergen Institute Discussion Paper
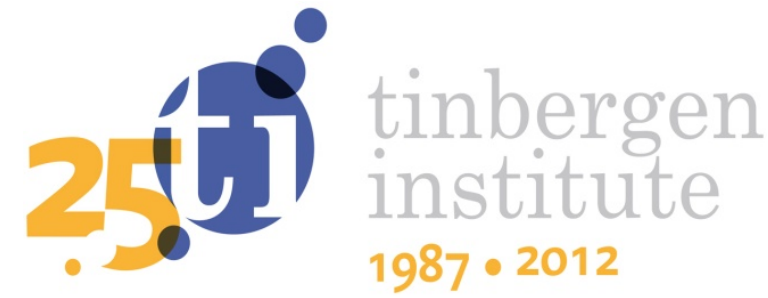

\title{
Social Interactions and Crime Revisited: An Investigation Using Individual Offender Data in Dutch Neighborhoods
}

Wim Bernasco'

Thomas de Graaff

Jan Rouwendal2

Wouter Steenbeek ${ }^{1}$

${ }^{\prime}$ Netherlands Institute for the Study of Crime and Law Enforcement, Amsterdam, The Netherlands;

2 Faculty of Economics and Business, VU University, Amsterdam, The Netherlands. 
Tinbergen Institute is the graduate school and research institute in economics of Erasmus University Rotterdam, the University of Amsterdam and VU University Amsterdam.

More TI discussion papers can be downloaded at http://www.tinbergen.nl

Tinbergen Institute has two locations:

Tinbergen Institute Amsterdam

Gustav Mahlerplein 117

1082 MS Amsterdam

The Netherlands

Tel.: +31(0)205251600

Tinbergen Institute Rotterdam

Burg. Oudlaan 50

3062 PA Rotterdam

The Netherlands

Tel.: +31(0)10 4088900

Fax: $+31(0) 104089031$

Duisenberg school of finance is a collaboration of the Dutch financial sector and universities, with the ambition to support innovative research and offer top quality academic education in core areas of finance.

DSF research papers can be downloaded at: http://www.dsf.nl/

Duisenberg school of finance

Gustav Mahlerplein 117

1082 MS Amsterdam

The Netherlands

Tel.: +31(0)20 5258579 


\title{
Social Interactions and Crime Revisited:
}

\section{An Investigation Using Individual Offender Data in Dutch Neighborhoods*}

\author{
Wim Bernasco $^{\dagger 1}$, Thomas de Graaff ${ }^{2}$, Jan Rouwendal ${ }^{2}$, and Wouter Steenbeek ${ }^{1}$ \\ ${ }^{1}$ Netherlands Institute for the Study of Crime and Law Enforcement, Amsterdam, The \\ Netherlands \\ ${ }^{2}$ Department of Spatial Economics, VU University, Amsterdam, The Netherlands
}

\footnotetext{
*Acknowledgements: We thank the Dutch Police (KLPD) for providing access to crime data and the participants of the Vth Congress of the Spatial Econometric Association (SEA) and the 52nd European Congress of the RSAI (ERSA) for useful comments. All authors contributed equally to the paper and are listed in alphabetical order.

${ }^{\dagger}$ Correspondence: Wim Bernasco, Netherlands Institute for the Study of Crime and Law Enforcement (NSCR), P.O. Box 71304, NL-1008 BH Amsterdam, the Netherlands. Email: wbernasco@nscr.nl.
} 


\begin{abstract}
Using data on the age, sex, ethnicity and criminal involvement of 14.3 million residents aged 10-89 residing in 4,007 neighborhoods in the Netherlands, this article tests if an individual's criminal involvement is affected by the proportion of criminals living in their neighborhood of residence. We develop a binomial discrete choice model for criminal involvement and estimate it on individual data. We control for the endogeneity that may be related to the unobserved neighborhood characteristics and take into account possible biases that may result from sorting behavior. We find strongly significant social interaction effects and explore their implications for the presence of multiple equilibria and social multipliers.
\end{abstract}

Keywords: social interactions, neighborhoods, crime

JEL-classification: R1, R2 


\section{Introduction}

The geographic variability of crime is a longstanding puzzle that was already studied in the early 19th century by statisticians Quetelet (see Beirne, 1987) and Guerry (see Friendly, 2007). A seminal paper on the topic (Glaeser et al., 1996) analyzes data on 658 cities in the United States and 70 precincts in New York City. The findings demonstrate that for a variety of crime types, the geographic variability in crime rates cannot be explained by economic, social or legal differences between cities or precincts. The authors conclude that the remaining variability should be attributed to 'social interactions', a term that encompasses a variety of different non-market mechanisms but is seldom explicitly defined (Manski, 2000). A common theme in the literature on social interactions is the proposition that the optimal choice of an individual depends on the choices of others, in particular others with whom the individual interacts directly or vicariously. If people interact predominantly with others who are geographically nearby, these interactions may provide an alternative explanation for the geographical variability of crime. ${ }^{1}$

The present paper reconsiders the role of social interactions in crime using comprehensive and detailed data. One important advantage of our data is that it allows us to measure the potential sphere of influence of social interactions more precisely than has been possible in prior work on social interactions, both in terms of spatial scale and reference group. With respect to spatial scale, we use Dutch neighborhoods that have an average population of 4,000 residents and an average surface of 10 square kilometers (approximately 4 square miles), whereas most previous studies applied their model to larger entities, such as cities and precincts. The detailed spatial scale is not only important for statistical reasons (e.g., it assures less heterogeneity within and more heterogeneity between observations) but

\footnotetext{
${ }^{1}$ See, for instance, Case and Katz, 1991, Freeman et al., 1996 and Zenou, 2003 and the references cited in these papers for further empirical evidence, Ballester et al., 2010 for a theoretical analysis of delinquent networks in the tradition of Becker, 1968 and Calvo-Armengol and Zenou, 2004 for the presence of multiple equilibria.
} 
also from a substantive point of view. In order for the choices of individuals to be affected by the choices of others in their environment, they must be aware of these choices. Most individuals are much more likely to be aware of the behavior of residents in their own neighborhood than of the behavior of residents in remote parts of their city or region. In addition to measurement at a detailed spatial scale, we also consider the possibility that social interactions may be age-specific. Because age segregation is endemic in all societies (Hagestad and Uhlenberg, 2006), and consequently most individuals are more aware of the behaviors of peers in their own age groups than of those who are much older or much younger, and because the criminological literature emphasizes the role of peers in criminal decision-making, we also test age-specific social interactions.

A second advantage of our data is that they include individual choices. Our data refer to individual neighborhood residents, which allows us to analyze offender rates (percentages of neighborhood residents suspected of being involved in crime in a given year) rather than crime rates. This allows us to separate crimes from offenders, i.e. choices from agents. This contrasts with the study by Glaeser et al. (1996), which was based on crime rates, i.e. annual numbers of crimes per capita committed within the geographic boundaries of cities or precincts, forcing the authors to make assumptions on the numbers of crimes committed per criminal.

Another important advantage of our data is that it facilitates the inclusion of individual characteristics (sex, age and ethnic origin) that are strongly correlated with criminal involvement. This allows us to take into account stylized facts about individual determinants of criminal conduct, such as the over-representation of males, adolescents and non-native residents among the criminal population. Our analysis includes the age (16 categories), sex (male versus female), ethnic origin (native versus foreign), neighborhood of residence (4,000 neighborhoods) and criminal record of the complete registered 2006 population aged 10-89 of the Netherlands. The sample totals 14.3 million residents 
of whom just over 21,300 were registered for being suspected by the police of having committed a crime in 2006.

As is well known, the identification of endogenous social interactions is complicated by the 'reflection problem' (Manski, 1993), a

"problem that arises when a researcher observing the distribution of behavior in a population tries to infer whether the average behavior in some group influences the behavior of the individuals that comprise the group. (p. 532)"

Several approaches to identify social interactions have been used in the literature. For example, Glaeser et al. (1996) develop a model with three types of agents: die-hard law breakers, die-hard law abiders, and those whose behavior depends on that of a close neighbor, and take the predictions of this model to their aggregate data. Bertrand et al. (2000), who study welfare use, exploit differences between language groups and locations to identify network effects. Our empirical work is based on a binomial choice model of an individual's choice of whether or not to be a criminal. Explanatory variables include individual as well as neighborhood characteristics, one of which is the fraction of criminals residing in the neighborhood. Brock and Durlauf (2001) provide a set of conditions under which such endogenous social interactions are identified in binomial discrete choice models and can be separated from contextual effects. We employ the methodology of Berry et al. (1995), making use of a constructed instrumental variable inspired by the work of Bayer and Timmins (2007).

To anticipate our results, we find strongly significant social interaction effects, especially among young people, after controlling for the impact of unobserved neighborhood effects and after eliminating possible effects of sorting. Further, we find that the strongest interaction effects are present for property crimes, and that offenders that commit property crimes are significantly younger than those that commit violent crime. However, 
our models do not suggest that multiple equilibria are relevant for the Dutch case. Nor do they imply large social multiplier effects of criminal behavior.

The remainder of this paper is structured as follows. The next section discusses the economic and criminological literature on crime and social interactions. Section 3 addresses the model and the estimation methodology. Section 4 describes the data used. Section 5 presents the findings, after which the final section concludes and provides suggestions for future research.

\section{Literature}

In criminological research, it has long been observed that peer delinquency and individual delinquency are correlated, i.e. that those who break the law tend to associate with others who also break the law, although empirically the proposition is tested almost exclusively amongst juveniles, not adults. Two mechanisms have been hypothesized to underlie this correlation. The first mechanism is social learning (Akers, 1985; Sutherland, 1947), according to which criminal behavior is learned from delinquent peers. People are more likely to commit crime if peers also commit crime, and learning includes being taught the tangible techniques of committing crime, but also learning cognitive techniques of neutralization to overcome moral concerns (Sykes and Matza, 1957). This mechanism is an example of contextual interaction with regard to learning specific skills, as well as endogenous interaction because it implies behavioral interdependence (referring to the decomposition terms of behavioral similarity in groups by Manski, 1993).

The second mechanism is group selection. According to this argument, criminality itself is caused by other factors (such as weak social bonds or low self-control, see Gottfredson and Hirschi, 1990), and the propensity of an individual to be a criminal is not caused by the company of criminal friends. Instead, causality runs the other way: criminals 
tend to seek the company of other criminals. Because association is also based on geographical proximity (Festinger et al., 1950), peer group or neighborhood selection induces behavioral similarity in criminality. This mechanism is an example of correlated effects, as it is not driven by behavioral independence with respect to the decision to become a criminal.

The correlation between peer delinquency and individual delinquency is thus hypothesized to be affected by processes of selection and influence in social interactions between peers. In one of the first criminological studies to employ longitudinal network analyzes to study the causal ordering of selection and influence, Weerman, 2011 shows that only the average delinquency level of one's friends in the school network has a significant, although relatively small, effect on individual delinquent behavior. Patacchini and Zenou, 2012 also study delinquency in peer networks and find a 'conformism' effect of peers' delinquency for all crimes but especially for petty crimes.

Social influence thus seems to be important to explain the correlation between peer delinquency and individual delinquency. Measuring the full extent of social networks to identify and estimate social interactions may, however, be unnecessarily demanding, because social interactions are likely to play a role not only in networks of strong ties, but also in networks of weak ties. Social interactions may even work vicariously, i.e. include mechanisms that do not rely on the identification of other individuals. For example, an individual's decision to commit crime may be affected by merely observing the behavior of unknown others, or even by just observing the outcomes of it (e.g., vandalism), and inferring the behavior.

In this paper, we focus on the endogenous interactions between neighborhood residents, and test the hypothesis that, all other things being equal, an individual's decision to be a criminal positively depends on the proportion of neighborhood residents that are criminals. Thus, we expect that one's behavior is influenced by observing or learning 
about the behavior of other neighborhood residents. Relevant examples for the purposes of this paper are $(i)$ see crime take place, $(i i)$ hear about crime taking place from offenders and/or victims in one's peer group, (iii) see the results of crime, and (iv) become a victim of crime. The neighborhood is an important context for studying the role of social interactions of crime. The focus on neighborhood as the presumed geographic unit of analysis where individuals interact with each other is logical, given the wealth of published research on neighborhood effects (for an overview of outcomes unrelated to crime, see Sampson et al., 2002).

We analyze property crime and violent crime separately as well as jointly in an overall measure that includes both types of crime. The rationale is that if criminal social interactions exist, they may be "crime type specific." This would mean that an individual's decision to become involved in property crime depends on the proportion of property offenders (but not on the proportion of offenders of violent crime) in his or her environment, and that the probability to become involved in violent crime depends on the proportion of violent offenders (but not on the proportion of property offenders) in the area. Violent crime includes offences like assault, domestic violence and robbery. Property crime includes offences like burglary, shoplifting and fraud. Because violent crime has a strong reciprocal nature (assault often takes place for reasons of revenge, and the perpetrators of assault are often identified while those of property crime often are not), we hypothesize that the social interaction effect for violent crime is larger than for property crime.

\section{The Model}

This section presents the model and the method of estimation. We use a binomial logit model for the choice whether or not to be a criminal. This choice is determined by personal characteristics as well as neighborhood characteristics. Idiosyncratic differences 
in individual choice behavior are captured by the conventional logit error term. We also address unobserved neighborhood effects by introducing elements of the approach pioneered by Berry et al., 1995 along the lines of Walker et al., 2011 in their model of social interactions in travel mode choice. Subsequently, we deal with the issue of correct identification of the social interaction effect, and we address the endogeneity of the social interaction effect. The final subsection discusses an implication of our model: the existence of multiple neighborhood offender rate equilibria.

\subsection{The choice of whether or not to be a criminal}

The model we use focuses on an individual's choice of whether or not to be a criminal. The choice depends on personal and neighborhood characteristics, not all of which are observed. Let $C_{i j}$ be a zero-one variable that indicates whether individual $i$ in neighborhood $j$ is a criminal. The probability that $C_{i j}$ equals 1 depends on personal characteristics $X_{i j}$, and on neighborhood characteristics $Z_{j}$. A social interaction effect is present if the expected value of the offender rate in neighborhood $j, C_{j}$, has an impact on the probability that a particular individual $i$ chooses to be a criminal. Since we are not informed about all the relevant characteristics, we introduce two random variables representing unobserved characteristics: $\epsilon_{i j}$ for unobserved personal characteristics and $\xi_{j}$ for unobserved neighborhood characteristics. We now define a latent variable $y_{i j}$ that is linear in these characteristics:

$$
y_{i j}=\alpha X_{i j}+\beta Z_{j}+\gamma E\left(C_{j}\right)+\xi_{j}+\epsilon_{i j} .
$$

When this latent variable takes on a positive value, $C_{i j}=1$, otherwise $C_{i j}=0$.

If we assume the random variable $\epsilon_{i j}$ to be extreme value type I distributed the probability 
that $C_{i j}=1$ is given by the logit expression:

$$
\operatorname{Pr}\left(C_{i j}=1\right)=\frac{e^{\alpha X_{i j}+\beta Z_{j}+\gamma E\left(C_{j}\right)+\xi_{j}}}{1+e^{\alpha X_{i j}+\beta Z_{j}+\gamma E\left(C_{j}\right)+\xi_{j}}}
$$

Without the social interaction and unobserved neighborhood effects (i.e., $\gamma=\xi_{j}=0$ ), this is a standard binomial logit model. When there is social interaction, but no unobserved heterogeneity $\left(\xi_{j}=0\right)$, this is the logit version of the binomial model of Brock and Durlauf (2001).

The unobserved heterogeneity term $\xi_{j}$ captures neighbourhood characteristics that may have an impact on an individual's probability to become a criminal, but are unobserved by the analyst. The importance of such unobserved heterogeneity in discrete choice models is analyzed thoroughly by Berry (1994) and Berry et al. (1995) in their seminal study of the automobile market. Their approach is used in other fields as well. For instance, Walker et al. (2011) apply a model like (2), but without neighborhood variables $Z_{j}$, to study the effect of social interactions on travel mode choice.

\subsection{Identification}

Berry et al. (1995) suggest a two-stage procedure. In the first step the neighborhoodspecific terms are taken together in a single neighborhood constant $\delta_{j}$.

$$
\operatorname{Pr}\left(C_{i j}=1\right)=\frac{e^{\alpha X_{i j}+\delta_{j}}}{1+e^{\alpha X_{i j}+\delta_{j}}}
$$

and this model is estimated in the usual way. In the second stage the alternative specific constants are analyzed further by writing them again as:

$$
\delta_{j}=\beta Z_{j}+\gamma E\left(C_{j}\right)+\xi_{j} .
$$


The unobserved heterogeneity terms $\xi_{j}$ are now the residuals of the linear regression equation. Manski, 1993 studies identification of a linear model with social interactions in which there are endogenous interaction effects as well as contextual effects. In our model the variable $E\left(C_{j}\right)$ embodies an endogenous social interaction effect, while contextual effects may be included in the vector $Z_{j}$ when it contains variables like the average age of neighborhood inhabitants. In Manski's model, the two effects cannot be distinguished. Brock and Durlauf, 2001 show that the nonlinearity that occurs in a discrete choice model like (2) has identifying power. They develop a set of conditions under which all the remaining parameters are identified. These conditions apply to the model (2) when the term referring to unobserved heterogeneity is absent.

The model (2) is identified if the parameters $\alpha$ and $\delta$ in (3) are identified and if the parameters $\beta$ and $\gamma$ in (4) are identified. Manski (1988) shows that the multinomial logit model is identified, so $\alpha$ and $\delta$ in (3) is not a problem. In Manski's linear model $C_{i j}$ is on the left-hand side of the linear equation of interest, whereas in (4) it is the estimated neighborhood-specific constant $\delta_{j}$. This is the reason why Manski's reflection problem does not occur in the present context. This implies that $\beta$ and $\gamma$ in (4) also do not cause problems.

However, there is another problem that has to be faced: the term $\xi_{j}$, which represents unobserved heterogeneity, has an impact on all $C_{i j}$ 's and therefore also on $E\left(C_{j}\right) . E\left(C_{j}\right)$ is therefore expected to be correlated with $\xi_{j}$. The reason is that a high value of $\xi_{j}$ makes it more likely that any individual in the neighborhood is a criminal, which tends to increase $E\left(C_{j}\right)$. Hence the error term in (4) is not independent of the explanatory variables. In the next subsection we propose a solution to this problem using an instrumental variable approach. 


\subsection{Endogeneity}

As an instrument we need an additional variable that is correlated with $E\left(C_{j}\right)$, but orthogonal to $\xi_{j}$. Since it is difficult to find such variables, ${ }^{2}$ we will construct such an instrument on the basis of the structure of the model, adapting an idea that was developed originally by Bayer et al., 2004. The basic idea is that our model can be used to predict the offender rates that would be observed if there would not be unobserved heterogeneity, that is if all $\xi_{j}$ 's would be equal to zero. These predicted offender rates are, by construction, independent of the $\xi_{j}$ 's, and are likely to be strongly correlated with the actual, observed offender rates. ${ }^{3}$ Moreover, these counterfactual offender rates clearly satisfy the exclusion restriction.

To see how the procedure works, start by observing that, according to the model, the expected offender rate is:

$$
E\left(C_{j}\right)=\left(\sum_{i \in j} \frac{e^{\alpha X_{i j}+\beta Z_{j}+\gamma E\left(C_{j}\right)+\xi_{j}}}{1+e^{\alpha X_{i j}+\beta Z_{j}+\gamma E\left(C_{j}\right)+\xi_{j}}}\right) / B_{j}
$$

where the summation is over all individuals living in neighborhood $j$ and $B_{j}$ is the total number of these individuals. It is easy to verify that in (5) there is a positive correlation between the unobserved neighborhood characteristics and the offender rate.

If we know the true values of the coefficients $\alpha, \beta, \gamma$ and the unobserved neighborhood characteristics $\xi_{j}$ we would be able to compute counterfactual choice probabilities, denoted as $I E\left(C_{j}\right)$ 's, for the situation in which unobserved neighborhood effects were absent,

\footnotetext{
${ }^{2}$ For instance, Walker et al., 2011 propose two types of instruments: a spatial reference group, or the average social interaction effect of the adjacent postal codes; and a social reference group, variables that indicate whether inhabitants of a neighborhood share similar socio-economic characteristics. However, these approaches are easy to criticize. It is not difficult to imagine social interactions that cross the often somewhat arbitrary boundaries of postal code areas, which would violate the exclusion restriction. It is also quite conceivable that the demographic composition of a neighborhood has a direct impact on the probability that some of its inhabitants become criminals.

${ }^{3}$ We report the first stage of one of the 2SLS regressions in the Appendix.
} 
that is for a situation in which all $\xi_{j}$ 's are equal to 0 . The $I E\left(C_{j}\right)$ 's are, by construction, uncorrelated with the $\xi_{j}$ 's, probably highly correlated with the $E\left(C_{j}\right)$ 's and satisfy the exclusion restriction. We thus use the exogenous characteristics $X_{i j}$ and $Z_{j}$ of individuals and neighborhoods to compute counterfactual choice probabilities for each individual that jointly predict counterfactual offender rates that are independent of the unobserved neighborhood characteristics.

The instrument is thus computed by removing the unobserved heterogeneity terms $\xi_{j}$ from (5) and computing the expected offender rate implied by the resulting equation:

$$
I E\left(C_{j}\right)=\left(\sum_{i \in j} \frac{e^{\alpha X_{i j}+\beta Z_{j}+\gamma I E\left(C_{j}\right)}}{1+e^{\alpha X_{i j}+\beta Z_{j}+\gamma I E\left(C_{j}\right)}}\right) / B_{j} .
$$

A complication associated with implementing the suggested procedure is that (6) uses the true (estimated) coefficients of the model, which can only be obtained through the use of the instrument. Bayer et al. (2004) and Bayer and Timmins (2007) therefore propose an iterative procedure in which one starts with an informed guess of the instrument values, ${ }^{4}$ then computes the coefficient estimates and use them to re-compute the instrument, until convergence is achieved.

A possible concern with this procedure is that not all of the characteristics $X_{i j}$ and $Z_{j}$ are exogenous. It is conceivable that some of them are correlated with the unobserved neighborhood characteristics. We come back to this in the results section.

\subsection{Social interaction and multiple equilibria}

The implications of the presence of social interaction in our choice model at the neighborhood level can be investigated on the basis of (5). We can interpret the right-hand

\footnotetext{
${ }^{4}$ One can, for instance, use the OLS estimates of (4).
} 
side of this equation as a mapping of $E\left(C_{j}\right)$ into itself. To focus on essentials, we assume a neighborhood populated by individuals that are identical (apart from the idiosyncratic term in the logit model) and simplify (5) as:

$$
E\left(C_{j}\right)=\frac{e^{\phi_{j}+\gamma E\left(C_{j}\right)}}{1+e^{\phi_{j}+\gamma E\left(C_{j}\right)}}
$$

In this equation $\phi_{j}$ summarizes all other neighborhood and individual characteristics. It is not difficult to verify that:

$$
\frac{d E\left(C_{j}\right)}{d \phi_{j}}=\frac{1}{1-\gamma E\left(C_{j}\right)\left(1-E\left(C_{j}\right)\right.} E\left(C_{j}\right)\left(1-E\left(C_{j}\right)\right)
$$

The first term on the right-hand side is a multiplier that equals 1 if there is no social interaction $(\gamma=0)$ and is larger than 1 whenever there is positive social interaction $(\gamma>0)$. As noted above, this multiplier could be responsible for spatial variation in offender rates that is much larger than one would expect on the basis of a model without endogenous social interactions.

Brock and Durlauf (2001) provide an analysis of the equilibria in this model. They show that for positive values of $\gamma$ there may exist three equilibria. Figure 1 illustrates this situation for $\phi_{j}=4$ (based upon average estimation results we discuss below) and various values of $\gamma$. Equilibria occur where the curves cross the 45-degree line. For $\gamma=0.1$ and $\gamma=0.15$ there are indeed three equilibria. The high and stable equilibrium refers to a situation in which almost everybody is involved in criminal activities. In the other two equilibria criminals are a minority, but the size of the minority differs significantly. The proportion of criminals equals either 1.5 percent or 15 percent (for $\gamma=0.15$ ) or 33 percent (for $\gamma=0.10$ ). the 1.5 percent equilibrium is stable, but the other two are not. The next section shows that the average offender rate in the Netherlands lies around 1.5 percent. However, the next section shows as well that there is substantial spatial variation in offender rates. This example therefore suggests that the model can be consistent with 
the presence of a different proportion of criminals in neighborhoods that are similar in all characteristics. Although the exact location of the equilibria depends on individual and neighborhood characteristics, our numerical experiments suggest that the offender rate at the stable equilibrium with the highest offender rate is unrealistically high.

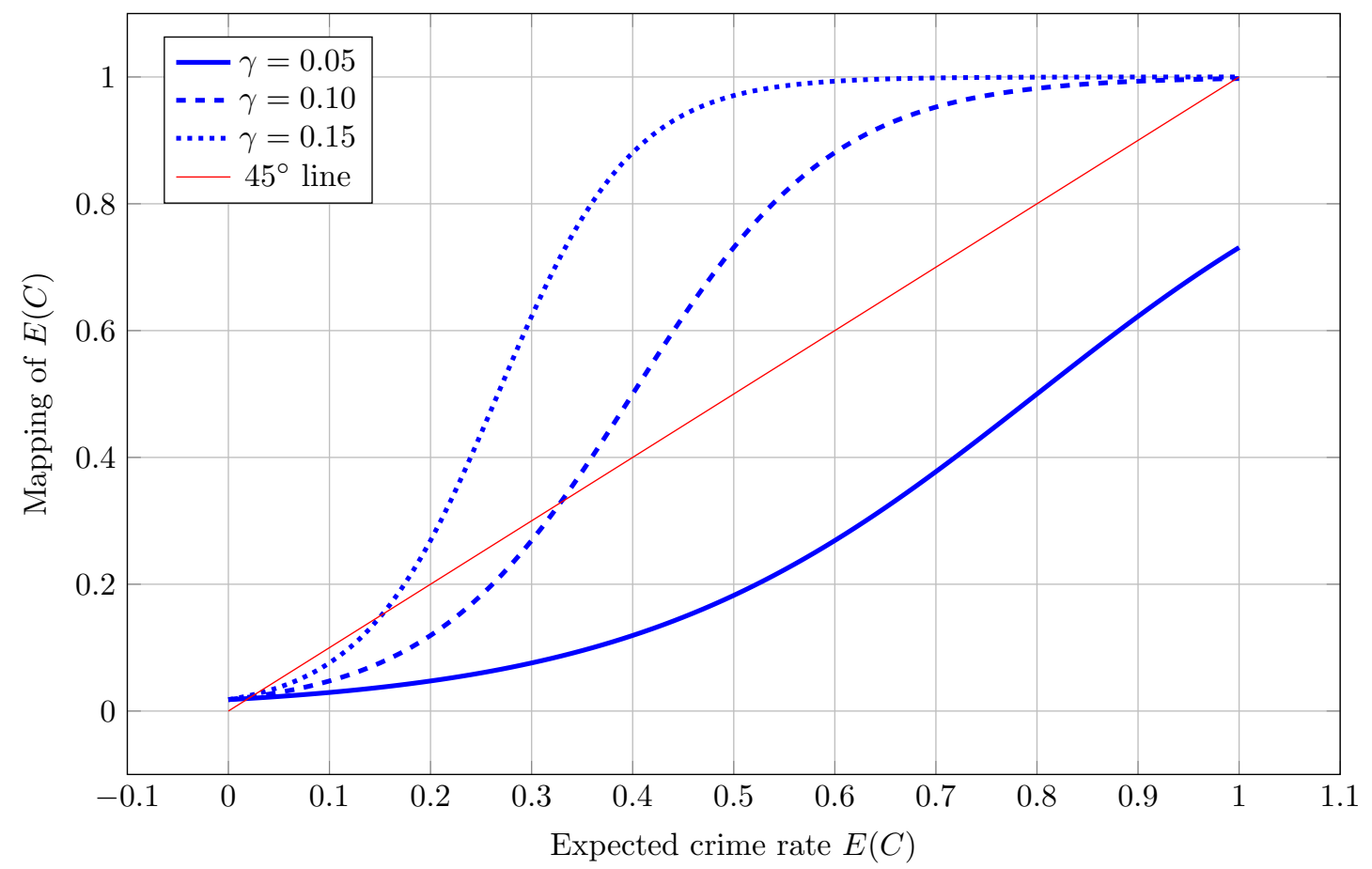

Figure 1 - Possible equilibria for multiple forms of crime based on $\phi_{j}=-4$ and various $\gamma$ values

\section{Data}

Criminal behavior is notoriously difficult to measure. Because it is morally objectionable and legally sanctioned, many people are unwilling to confess their involvement in crime, to law enforcement as well as to researchers. Although quite a few surveys ask adolescent subjects to report their involvement in criminal conduct (a few examples include Elliott et al., 1985; Farrington et al., 1996; Wikström et al., 2012) crime self-report surveys are rare among adult populations (but see Morselli and Tremblay, 2004). 
To measure criminal behavior we therefore used anonymized national population data from the Dutch National Police. The police information system from which the data were extracted contains data on all individuals who have been arrested by the Dutch police as criminal suspects in a particular year. It is estimated that more than 90 percent are subsequently either convicted in court or imposed a fine or community service by the public prosecutor's office in lieu of prosecution (this often happens in the case of relatively minor crimes) (Blom et al., 2005). The data contain some personal characteristics (sex, age, country of birth, parents' countries of birth, postal code of residential address) and also contain details about all crimes of which the individual has been suspected (including the dates and the types of crime). In the analysis in this paper we use being a suspect of any crime(s) in the year 2006 as the dependent variable as well as separate indicators for being suspected of $(i)$ violent and (ii) property crime. Violent crime includes homicide, assault, sexual assault, and robbery, property crime includes burglary, larceny, theft, arson and vandalism. The two types do not exclude each other, so that a single person can be suspected of both crimes types within the same year.

Because the police information system is used for investigative purposes, it is updated continuously, and updates include changes of address as well as removal of individuals after an expiration period, the length of which depends on the seriousness of their criminal record. The database used in this analysis was an archival copy of the information system, and included crimes already removed from the real 'living' information system. Data from special investigative services are excluded, so that tax and other economic crimes, social security fraud, and environmental crimes are underrepresented.

There are some (well-documented) disadvantages of using police records to measure criminality. First, a substantial percentage of crimes never come to the attention of the police, either because there is not an individual victim to report it (e.g., drug dealing) or because the victim does not report the crime to the police (Goudriaan et al., 2004). 
Second, in most jurisdictions the police solve only approximately 20 percent of all crimes (Dodd et al., 2004). As a consequence, any estimate of criminality based on police data must be a severe underrepresentation. Third, specific surveillance or investigative strategies used by the police may result in some areas being more intensely supervised and investigated than others, resulting in an overrepresentation of these areas in the data. Fourth, police records have data on suspects, but some of these people may be unjustly suspected and will not be convicted subsequently in court. Notwithstanding these limitations police records are the best available large-scale measures of criminality available, and have been used extensively in previous studies in the Netherlands and abroad.

To obtain a full population dataset on criminal involvement in 2006 in the Netherlands, we used population data from Statistics Netherlands per January 1st, 2006, which crosstabulates neighborhood of residence (4,028 neighborhoods) with age (20 categories, each 5 years width), sex (male versus female), and ethnicity (native versus non-native). As the police records contain these four variables as well, both sources can be combined to create a national dataset containing approximately 16 million individuals with the following five variables:

1. neighborhood of residence (4,028 neighborhoods);

2. sex (male or female);

3. non-native Dutch (individual or their parent(s) born in a non-western country, or not)

4. age (20 categories: 0-4 years, 5-9 years, 10-14 years, 15-19 years, etc.);

5. suspected of one or more violent/property crimes in 2006 (yes or no). 
Because in the Netherlands only individuals of age 12 and older can be prosecuted, age categories $0-4$ years and 5-9 years were removed from the analysis. Persons aged 10 or 11 are included because the population data are available only in 5-years age categories. Because no individuals above age 89 were prosecuted in 2006, ages 90 and above were also removed from the analysis. The remaining dataset contains 14,301,005 individuals aged $10-89$ in 2006.

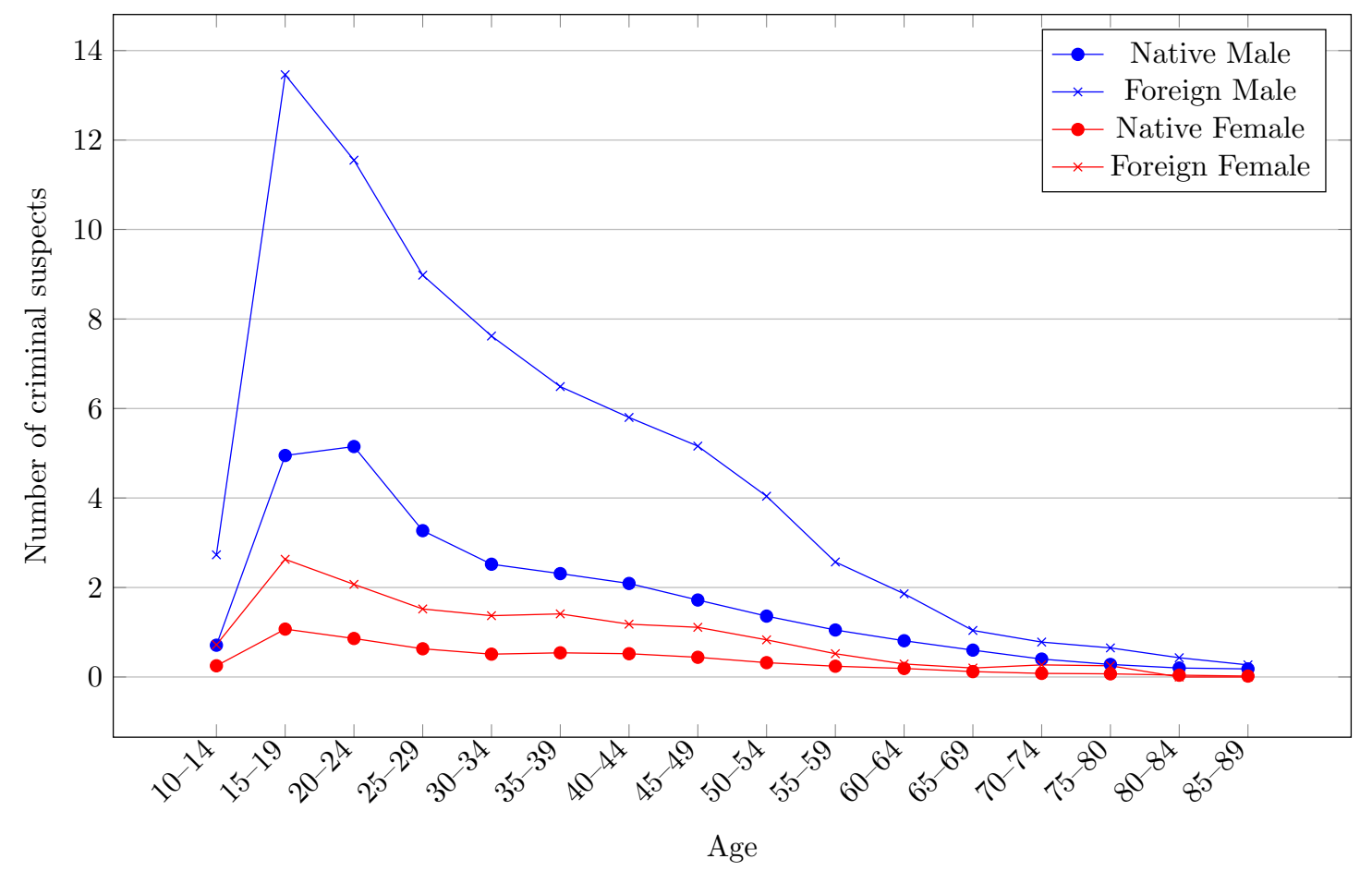

Figure 2 - Number of criminal suspects in 2006 per 1000 individuals, by age, sex, and ethnic origin

For this population, Figure 2 displays the number of individuals who were suspected of criminal involvement during the year 2006, per 1,000 residents of the same sex, age category and ethnic origin. ${ }^{5}$ The figure confirms three stylized facts about criminality: the arrest rates of men are five times larger than those of women (Mears et al., 1998; Steffensmeier and Allan, 1996), the arrest rates of residents with foreign origin are more than 3 times larger than those of native Dutch residents (Blokland, et al. 2010), and

\footnotetext{
${ }^{5}$ The data underlying Figure 2 are included in Table 3 in the Appendix.
} 
arrest rates of all groups peak during adolescence and early adulthood at ages 15-24 (Blokland et al., 2005). On average, 1.5 percent of the 10--89 population became a crime suspect in 2006. For boys in the age category 15-24 years, the percentage is more than four times larger than the average.

The police records include the six-digit postal codes of the residential addresses of the individuals. Throughout the Netherlands there are about 435,000 six-digit postal code areas. In non-rural areas they are roughly the size of a football field and contain approximately 20 residential properties and 40 residents. As they were created with pedestrian postal delivery services in mind, single codes are nearly always on the same street, apply to adjacent properties, and are not subdivided by physical barriers that impede pedestrian or car transportation. The focus of our investigation is the proportion of neighborhood residents involved in crime. ${ }^{6}$ In line with definitions of 'neighborhood' as a locus of social interaction elsewhere in the literature, our analysis uses the four-digit Dutch postal code number as the spatial unit of analysis, i.e. a spatial aggregation of the six-digit postal code. Following Walker et al. (2011), we assume that

these postal code boundaries delineate spatial peers and that individuals within a postal code are more similar, exerting a stronger influence than individuals who live outside of one's postal code. (p. 368)

Many other studies in the Netherlands have used the four-digit postal code as a neighborhood delineation criterion (e.g., Bernasco and Kooistra, 2010; Nieuwbeerta et al., 2008; Wilsem et al., 2006).

Substantive arguments for neighborhood as a valid spatial reference group were already given in the literature overview. There are also several methodological arguments in

\footnotetext{
${ }^{6}$ When the peer group is located in the neighborhood, the chance of interaction with a criminal is affected not only by the relative number of criminals, but also by the size of the area. Thus, the social interaction effect can alternatively be defined as the percentage of residents per square mile exhibiting a given behavior.
} 
favor of the neighborhood (instead of a larger or smaller spatial unit). First and foremost, larger areas such as cities ensconce within-city heterogeneity (and therefore betweenneighborhood differences) in criminality. Secondly, smaller areas than neighborhoods, such as streets, result in very skewed crime distributions that are more difficult to model properly. Thirdly, no or very little areal data are available at smaller spatial scales than neighborhoods. Because previous scholars have used cities as units of analysis, we bolster our argument for smaller areal units by presenting the percentage of criminal suspects graphically for both municipalities and neighborhoods in the Netherlands in Figure 3.
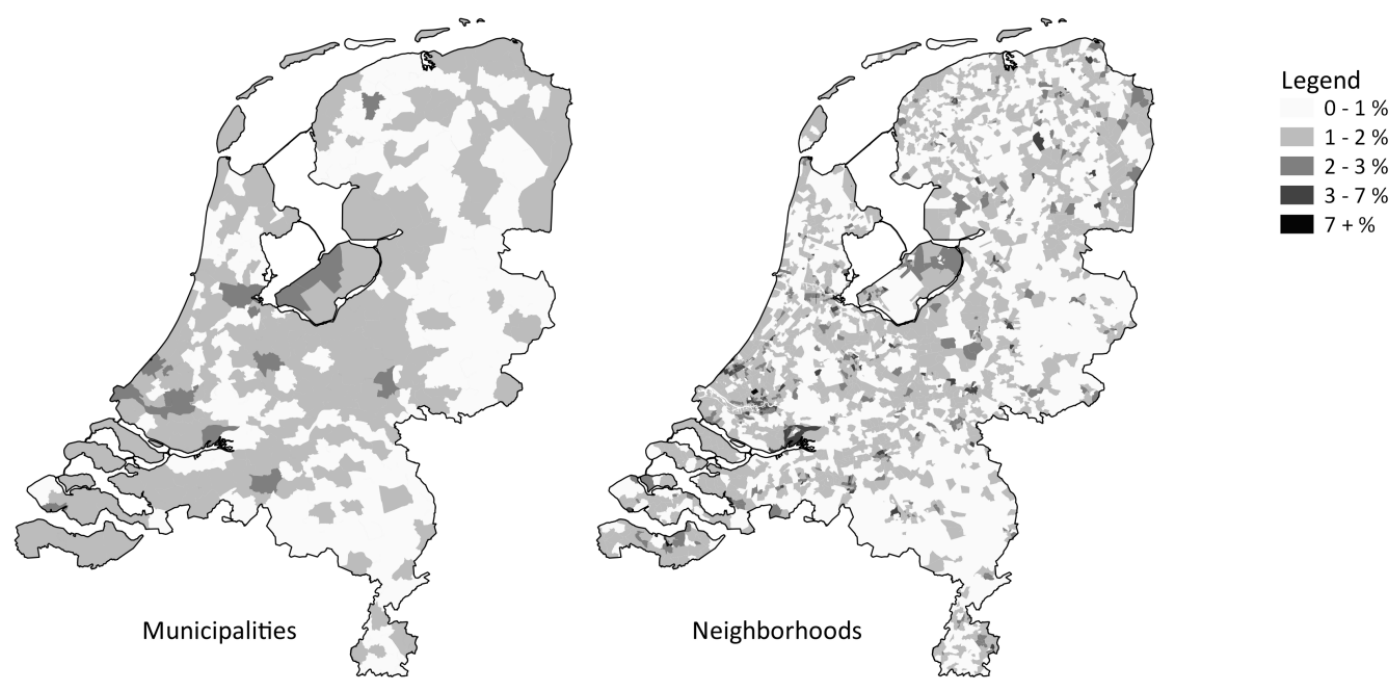

Figure 3 - Percentage of criminal suspects in 2006 per municipality and neighborhood (data: HKS; maps (C) Kadaster / Centraal Bureau voor de Statistiek, 2013)

Figure 4 provides a view of neighborhoods in Amsterdam, the capital of the Netherlands. These figures show that the percentage of criminal suspects per municipality disguises large within-municipality differences. For example, whereas 2.2 percent of the population of Amsterdam was suspected of a crime in 2006 (1.8 percent and 1.2 percent for violent 
crime and property crime, respectively), the percentage of suspected criminals per neighborhood ranges from 0 percent to about 5 percent $(0-4$ percent and $0-3$ percent for violent crime and property crime, respectively).

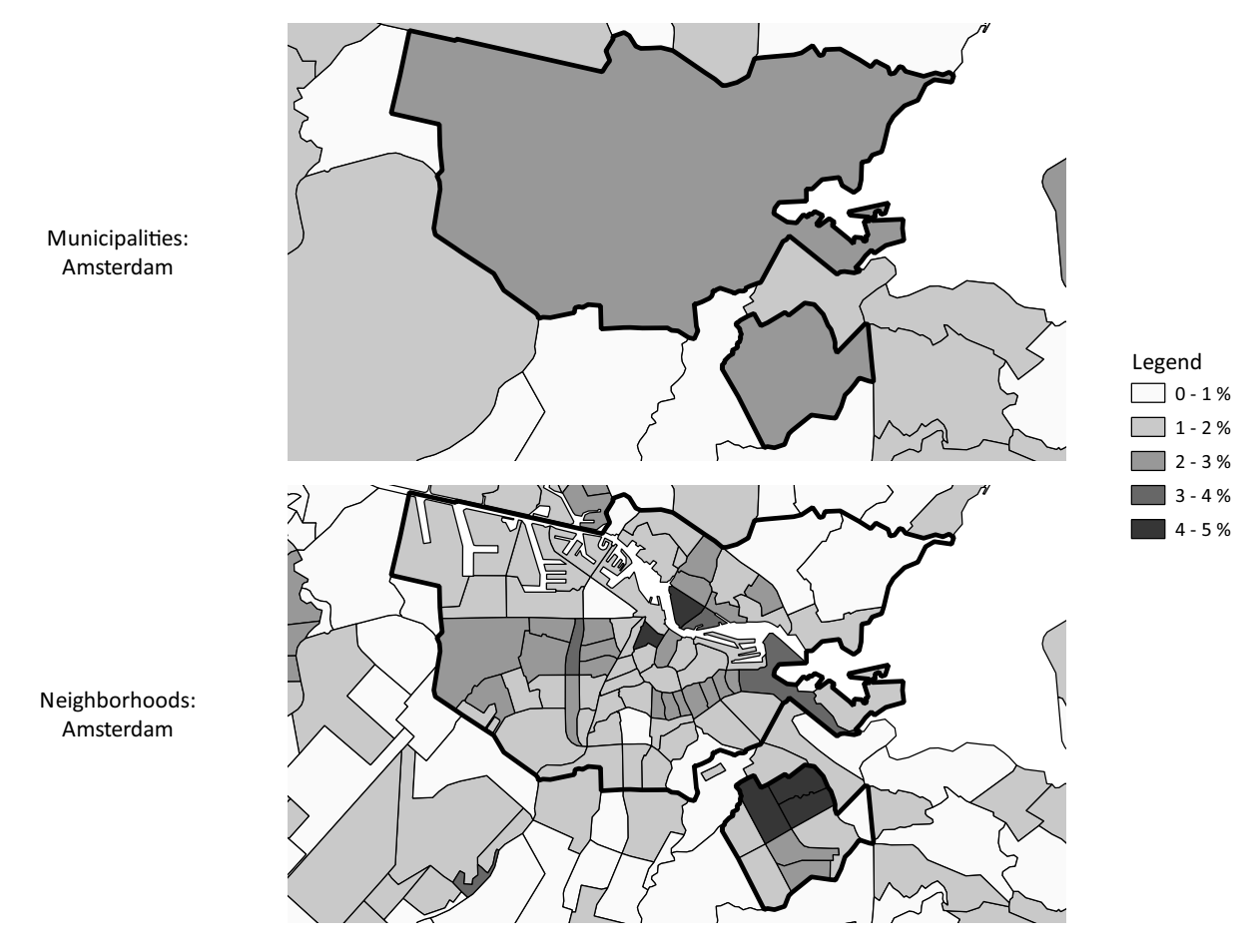

Figure 4 - Percentage of criminal suspects in 2006 Amsterdam neighborhoods (data: HKS; maps Kadaster / Centraal Bureau voor de Statistiek, 2013)

Geographically, the Netherlands is a small country with a total land surface of 41,526 square kilometers. The total country consists of 4,028 four-digit postal code areas with an average surface of 10.31 square kilometer and an average population of 4,073 inhabitants. Similar to US census tracts, the sizes of these 'neighborhoods' depend on population density. In urban areas where population densities are high, the surfaces of neighborhoods tend to be relatively small, whereas they are larger in rural areas where population densities are low.

To account for possible spurious findings, we control for several ubiquitous variables in 
criminological research about neighborhood differences in crime. Classic and contemporary criminological studies have consistently found that high population turnover, ethnic heterogeneity, low socio-economic status and the presence of one-parent households correlate with higher offender rates (e.g., Bursik Jr. and Grasmick, 1993; Glaeser and Sacerdote, 1999; Sampson and Groves, 1989; Sampson et al., 1997). These neighborhood characteristics are hypothesized to affect crime in two distinct ways: $(i)$ by decreasing social cohesion and (expectations of) social control; ( $i i)$ by impeding proper socialization of youth by parents and other neighborhood residents. We therefore merge our dataset with two additional neighborhood datasets. The first is the neighborhood data from the Dutch Central Bureau of Statistics from which we extract address density, percentage single person households, average household size, number of shops, percentage owneroccupied housing, school density and percentage single parent households. The second is the Geomarketing data from WDM Netherlands, which is in itself composed out of several (marketing) databases. This database gives us information about neighborhood mobility (in- and out-migration), average level of education, a measure for the average social class and the number of double income households within a neighborhood.

In addition, we aim to control for the effect of the presence and activities of law enforcement agencies. To that effect we use data from the Dutch Police Population Monitor of 2005, a bi-annual (cross-sectional) victimization survey spanning the entire Netherlands $(\mathrm{n}=52,560)$. Several questions in this survey deal with the perception of the neighborhood by its residents. We aggregated the individual survey responses about the 'perceived availability of the police' in their neighborhood to the four-digit postal code level. Perceived 'availability of the police' is a combination of agreement ratings of five statements: "You don't see the police enough in this neighborhood", "They don't exit their vehicles often enough", "They are not approachable enough", "They do not have enough time for many things", "They don't come quickly when you call them" $(0=$ agree, $1=$ don't agree, don't disagree, 2 = disagree, with "don't know" recoded to answer category 1). The responses 
to these five questions were summed, resulting in a scale ranging from zero to ten (higher values indicating better availability). The mean of these individual-level summary values per four-digit postal code is the final 'availability of police per neighborhood' variable (n $=3,356$, mean $=4.8$, sd. $=1.5)$.

Finally, it is well conceivable that the impact of social interaction varies with residential density. Denser neighborhoods might lead to more residential interaction because meeting probabilities are larger. ${ }^{7}$ To control for this effect we incorporate an interaction effect between social interaction and residential density.

\section{Results}

In this section we present estimation results. We start, in subsection 5.1, with the basic model of equation (3) and estimate it for the total population. Since it may be argued that social interactions are especially important among adolescents, who are also the most frequent offenders, we then estimate the model only for the group aged between 12 and 18. The results are discussed in 5.2. Possible effects of sorting are probably less relevant for this group since most of them did not choose their own residential location. However, sorting may still be a concern when parents' characteristics are correlated with those of their children. As this is probably the case, we also present, in 5.3, a version of the model in which indicators of neighborhood demographics have been replaced by averages over municipalities. The argument to support this specification is that choice of a residential neighborhood takes place within a larger (labor market) region that is taken as given by a household (see as well, e.g., Evans et al., 1992). This implies that the demographic characteristics of this larger area are also taken as given, whereas those of smaller geographical units are selected by the residential location choices of households.

\footnotetext{
${ }^{7}$ See, for instance, Glaeser and Sacerdote (1999) for more discussion.
} 
An additional advantage of the switch to averages of demographic characteristics of larger areas is that it removes the possible effects of differences in policing that are related to the neighborhood demographics (e.g., areas may have less or more intensive police surveillance) from the model. In this model we also find significant endogenous social interaction effects, for the total population as well as for the young.

\subsection{The basic model}

Table 1 presents the estimation results of equation (3) for the entire Dutch population, omitting the neighborhood-specific constants $\delta_{j}$. The socio-demographic variables included are a sex indicator ( 0 for males, 1 for females), an ethnicity indicator ( 0 for native Dutch or born in a western country, 1 for people or one of their parents born in a non-western country), age (measured categorically as $10-14=-1,15--19=0,20-24=$ $1, \ldots, 85-89=14$, i.e. centered on the peak of the age-crime curve) and age squared. Of the 4,007 neighborhoods there were 401 in which not a single resident offended in 2006, making it impossible to estimate a neighborhood-specific constant term for the general model. Violent offenders were absent in 409 neighborhoods, and property offenders were absent in 802 neighborhoods. ${ }^{8}$

The estimation results confirm the descriptive statistics visualized in Figure 2. Males and non-natives are much more likely to become involved in crime than females and native Dutch residents, and crime involvement quickly increases with age during adolescence and then gradually decreases. While the estimated parameters for violent crime are similar to the estimates for general crime, the property crime estimates indicate that the age-crime curve for property crime peaks at younger ages.

\footnotetext{
${ }^{8}$ Usually, only the smallest neighborhoods with few of no criminals fall out of the estimation, which might lead to a selection bias. Note, however, that the number of observations decreases much slower than the number of neighborhoods.
} 
Table 1 - Choice models (log-odds of being suspect of crime in 2006).

\begin{tabular}{|c|c|c|c|c|c|c|}
\hline \multirow[b]{2}{*}{ Parameter } & \multicolumn{2}{|c|}{ All crime } & \multicolumn{2}{|c|}{ Violent crime } & \multicolumn{2}{|c|}{ Property crime } \\
\hline & Estimation & S.E. & Estimation & S.E. & Estimation & S.E. \\
\hline Female & -1.637 & 0.0059 & -1.885 & 0.0069 & -1.509 & 0.0085 \\
\hline Non-native & 0.783 & 0.0059 & 0.743 & 0.0063 & 0.957 & 0.0081 \\
\hline Age & 0.070 & 0.0019 & 0.109 & 0.0021 & -0.110 & 0.0030 \\
\hline $\operatorname{Age}^{2}$ & -0.026 & 0.0002 & -0.030 & 0.0003 & -0.034 & 0.0004 \\
\hline \# Observations & \multicolumn{2}{|c|}{$14,191,721$} & \multicolumn{2}{|c|}{$14,189,082$} & \multicolumn{2}{|c|}{$13,966,926$} \\
\hline \# Parameters & \multicolumn{2}{|c|}{$4+3,610$ constants $(\delta)$} & \multicolumn{2}{|c|}{$4+3,602$ constants $(\delta)$} & \multicolumn{2}{|c|}{$4+3,209$ constants $(\delta)$} \\
\hline Log-likelihood & \multicolumn{2}{|c|}{$-961,220.0$} & \multicolumn{2}{|c|}{$-855,499.9$} & \multicolumn{2}{|c|}{$-491,169.2$} \\
\hline
\end{tabular}

A higher value of the neighborhood-specific constant $\delta_{j}$ means that, conditional on sex, age and ethnic origin, neighborhood residents are more likely to be involved in crime. The first-stage model imposes a structure on the effects of individual characteristics, but it is silent about the mechanisms underlying between-neighborhood variation: these have to be sorted out in the second stage. The kernel density estimates of the shape of the $\delta_{j}$ distributions are presented in Figure 5. All three density functions are single peaked and almost symmetric. The kernel density function of violent crime is similar to that of crime in general, whereas the kernel density function of property crime clearly has a higher mean and standard deviation.

Table 2 presents the results of the second stage. Of all three definitions of crime (all crime, violent crime and property crime) we first present the OLS results, and then the 2SLS results.

As instruments of Offender rate and Offender rate $\times$ density we used the counterfactual offender rate $\left(I E\left(C_{j}\right)\right)$ as defined in eqn. (6), and the multiplicative interaction effect of the counterfactual offender rate and the address density $\left(I E\left(C_{j}\right) \times\right.$ density $)$. Table 4 in the Appendix reports the results of the first-stage regression on our social interaction variable (Offender rate) and interaction effect (Offender rate $\times$ density). As these tables 


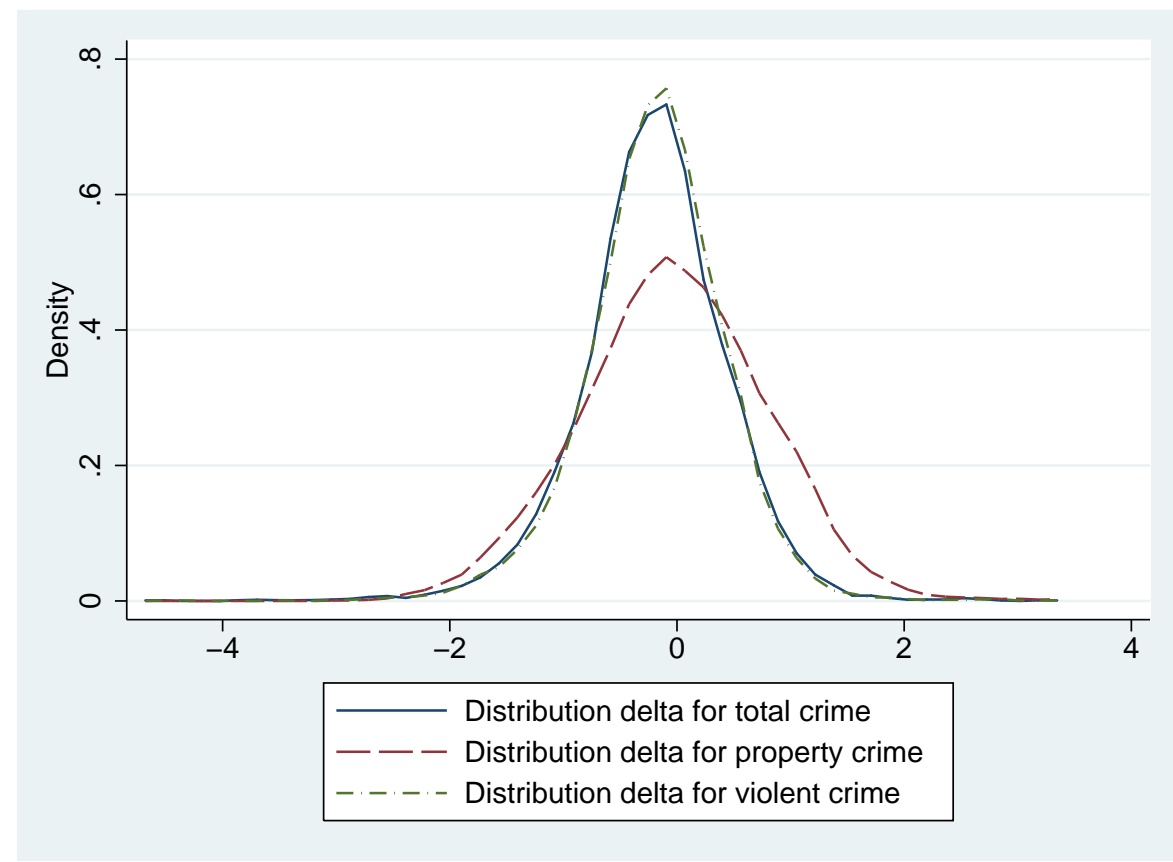

Figure 5 - Kernel density estimates of the distribution of $\delta$

clearly show, the instruments we use are relevant. The counterfactual offender rate is very significant and shows a positive correlation with offender rate, as expected. The counterfactual offender rate times the address density is very significant as well and shows a positive relation with the interaction term: Offender rate $\times$ density. By construction, the counterfactual offender is uncorrelated with the error term $\xi$.

Columns (I) and (II) in Table 2 present the most important results from our second stage regression on neighborhood constants for our total sample and covariates measured at the neighborhood level. Table 5 in the Appendix gives the full results of this regression, including the coefficients for the demographic control variables. The main conclusion s that the hypothesized social interaction effect (i.e., the effect of the neighborhood percentage of other residents involved in crime) that appears to be strong and highly significant in the OLS regressions disappears completely in the 2SLS results. The estimates of most other variables in the 2SLS estimation change little with one exception: the coefficient for single parent households was (unexpectedly) negative and in two cases 


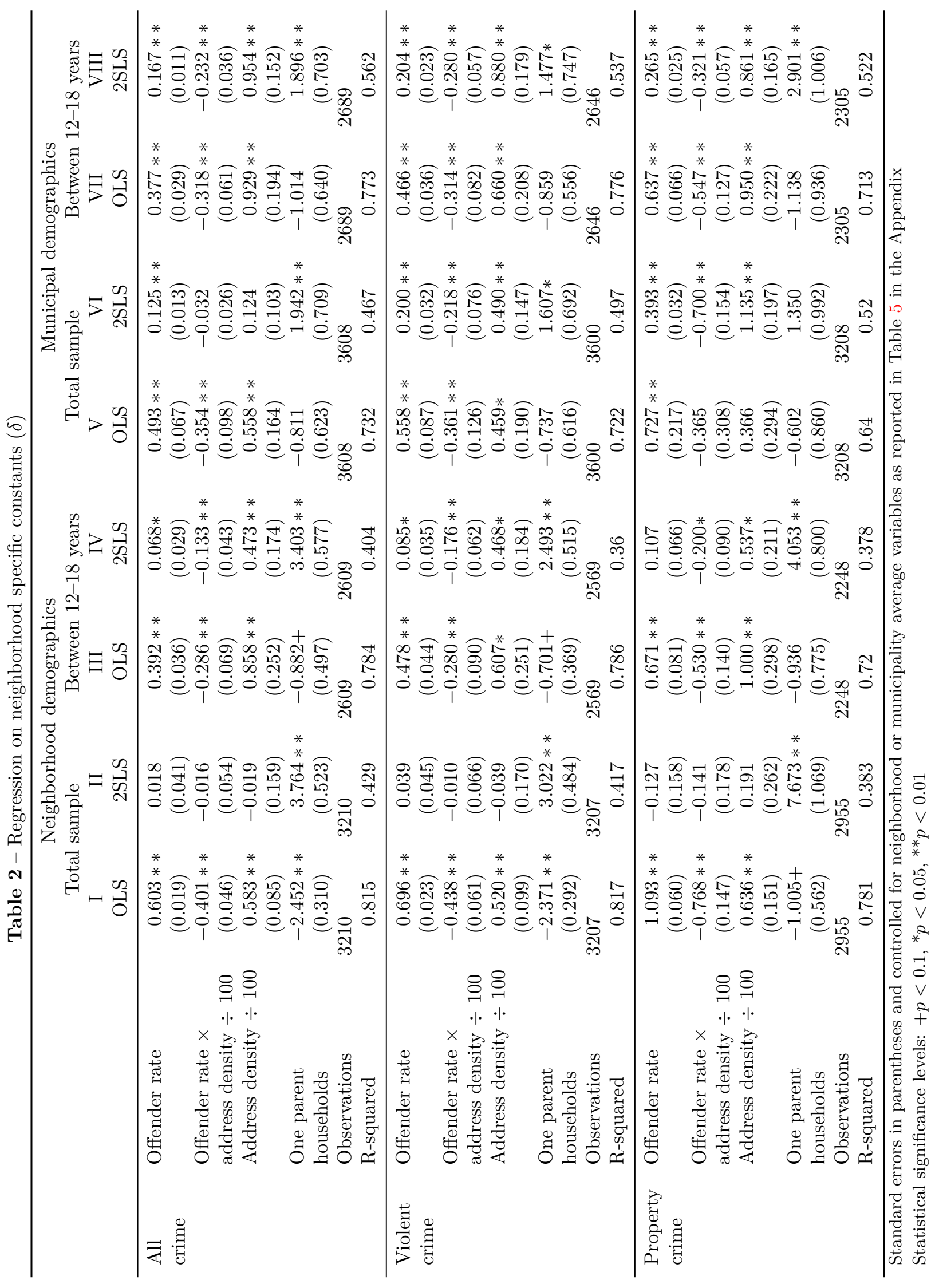


significant in the OLS regression, but becomes positive, larger in absolute value and strongly significant in the 2SLS regressions. A large and highly significant coefficient on the share of single parent households is in line with earlier analyses (notably Glaeser and Sacerdote, 1999).

The estimated coefficients of the other variables are in line with studies on neighborhood level correlates on crime and delinquency, which generally show that indicators of social and economic disadvantages (low education, low income, high neighborhood mobility and high proportions of single person and single parent households) are associated with more crime. ${ }^{9}$

\subsection{Only the young}

In columns (III) and (IV) in Table 2 we report estimation results for a sample of persons between 12 and 18 years. The results of the first stage (binomial logit) estimates are available from the authors upon request. From here we discuss only second stage results. As we have seen, most crimes are committed by young people, which makes it interesting to give separate attention to this group. It may also be conjectured that social interactions are more important for these persons. ${ }^{10}$ Lastly, a focus on the young may to some extent alleviate potential concerns about sorting effects, as they did not choose their residential neighborhood themselves. (Moreover, see section $\mathrm{C}$ for even further consideration of sorting effects.)

Columns (III) and (IV) confirm the general conclusion from (I) and (II) in that an

\footnotetext{
${ }^{9}$ Our results are robust over years (for the years 2007 and 2008 we get similar results) and to the specification used. Only if we omit single parent households we get somewhat higher social interaction effects (up to $\gamma=0.13-0.15$ ). Using different instruments, in particular the spatial lags of surrounding neighborhoods, does, however, significantly increase the social interaction effect (with a $\gamma$ above 0.4 , which leads to completely criminal neighborhoods, a highly implausible outcome).

${ }^{10}$ There is evidence of strong age segregation in social contacts, see, for instance, Hagestad and Uhlenberg (2006).
} 
apparently strong social interaction effect decreases substantially once we take into account the possible impact of unobserved neighborhood characteristics. However, the Offender rate variable now remains significant in two of the three cases. Moreover, we now find a significantly positive impact of density (addresses per hectare) and of the interaction between the offender rate and density for all crime and violent crime. We therefore conclude that for the young social interaction and an urban (high population density) environment are significant determinants of criminality.

\subsection{Municipal demographics}

There are two other concerns with the estimates presented thus far that we investigate further in this subsection. We noted already that sorting may disturb our results. Offender rates may affect the composition of the population in neighborhoods, for instance, because high income households avoid to locate in areas with a high share of criminals and become underrepresented there, while other household types, for instance those that experience more tight financial constraints, become overrepresented. If this happens, the share of criminals in the neighborhood becomes correlated with the demographic composition of that neighborhood and this complicates the measurement of the determinants of criminality. It may even be argued that this effect is present if we only consider the young people who did not themselves choose their residential neighborhood, since their characteristics are correlated with those of their parents through nature and nurture. To address the sorting issue, Evans et al. (1992), who use binomial choice models to study peer effects in teenage behavior (pregnancy and school dropout), propose the use of averages over larger geographical areas. They argue that sorting refers mainly to the choice of a neighborhood within a metropolitan area whereas households take the general demographic characteristics of this larger area as given. We follow their line of reasoning 
here and replace the demographic characteristics of the neighborhood ${ }^{11}$ by the average values of these variables in the municipality.

This reformulation of the model addresses a second concern. Bertrand et al. (2000) motivate the use of area-wide averages of welfare use as a means to avoid possible bias associated with unobserved characteristics that individuals in a particular neighborhood have in common with others who belong to the same group. In the context of the present paper, a potentially important effect is the attention given by the police to a particular neighborhood, which may well be correlated with the demographic characteristics of the neighborhoods. If the police has a given capacity per larger geographical unit our alternative specification should be expected to be more robust against this possible source of bias as well.

The results of the alternative specification for the total population and for the young only are presented in Table 2 in columns (V) and (VI), and (VII) and (VIII), respectively. For both samples we now find highly significant endogenous social interaction effects. Although in the 2SLS regressions these effects are smaller than indicated by simple OLS, they remain substantial. There is now also in all three cases a highly significant positive effect of address density, while the interaction effect is negative. We conclude from these results that sorting as well as possible differences in the attention the police pays to various neighborhoods had an important impact on the earlier results.

\subsection{Implications}

In this section we present the implications of our coefficient estimates for the equilibria. We start with investigating the implications of our model for the equilibrium offender

\footnotetext{
${ }^{11}$ The variables concerned are: density one parent households, average persons per household, average educational attainment, average social class, percentage double income households, percentage inand out-migration, percentage owner-occupied housing and average on-street police presence.
} 
rates. To do this we construct three diagrams similar to Figure 1, but based on our estimation results. These figures refer to a neighborhood in which all demographic variables have been set equal to their averages, and that is populated with individuals whose characteristics have also been set equal to the population averages. Although such neighborhoods do not exist, the curves constructed in this way give a reasonable impression of the curves that are relevant for actual neighborhoods with populations not deviating highly from the average.

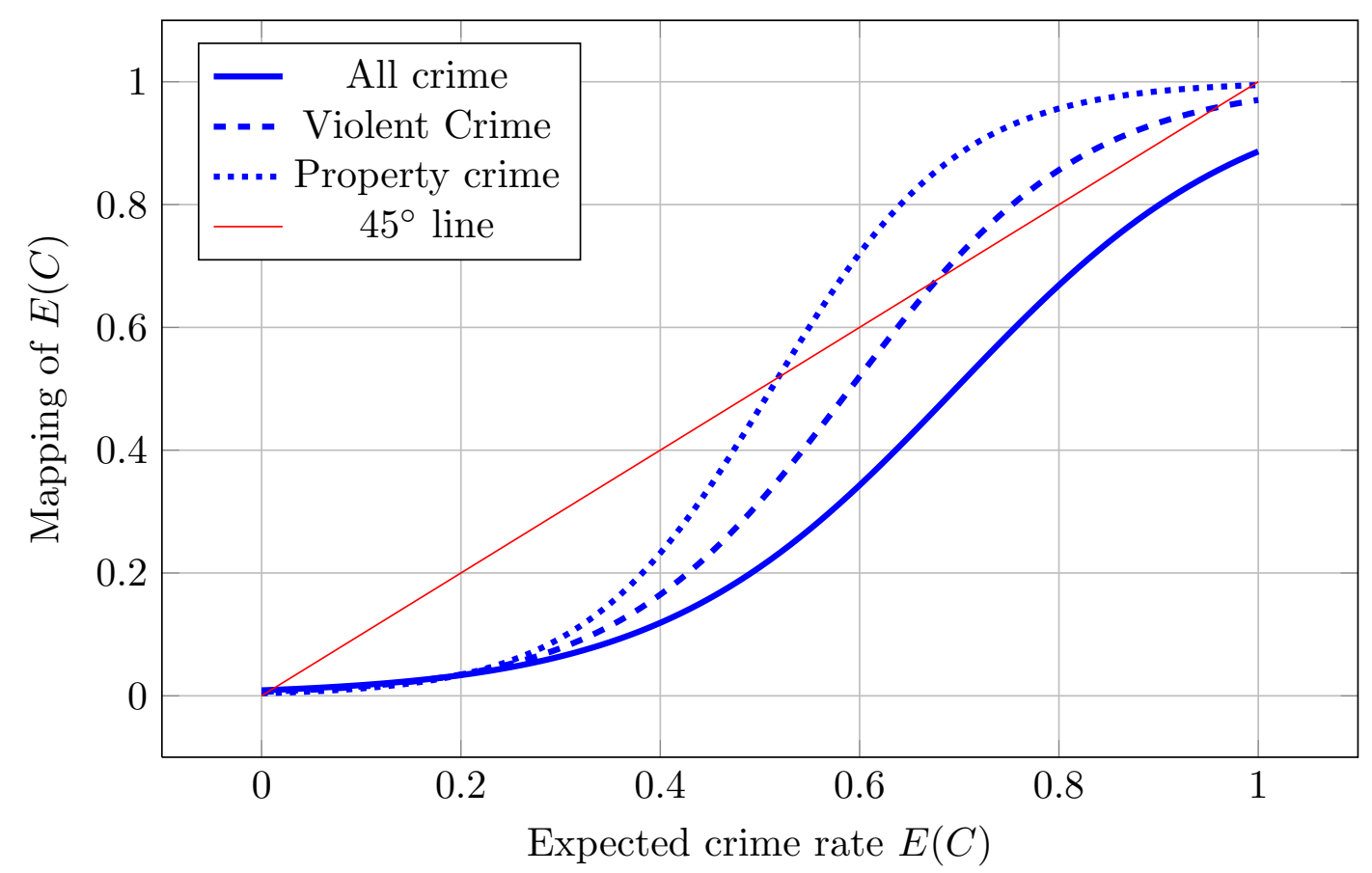

Figure 6 - Possible equilibria for multiple forms of crime based on parameter estimates for the youth and neighborhood-average exogeneous variables (with maximum offender rates for all crime, violent crime and property crime being 18.9, 15.7, 11.6 respectively)

Figure 6 is based on the estimates listed in column (IV) of Table 2. It illustrates that multiple equilibria for violent and property crime are possible in the model that refers only to the youth. In all three cases shown there is an equilibrium close to the 1,5 percent share where most of our data are. For violent and property crime there is a second stable equilibrium at a very high level_ close to 100 percent_ - of crime. The attraction 
basins of the two stable equilbria are separated by the third, unstable, equilibrium that is in both cases located above the maximum share of criminals in our data. These models do therefore not suggest that neighborhoods may switch from the low to the high equilibrium.

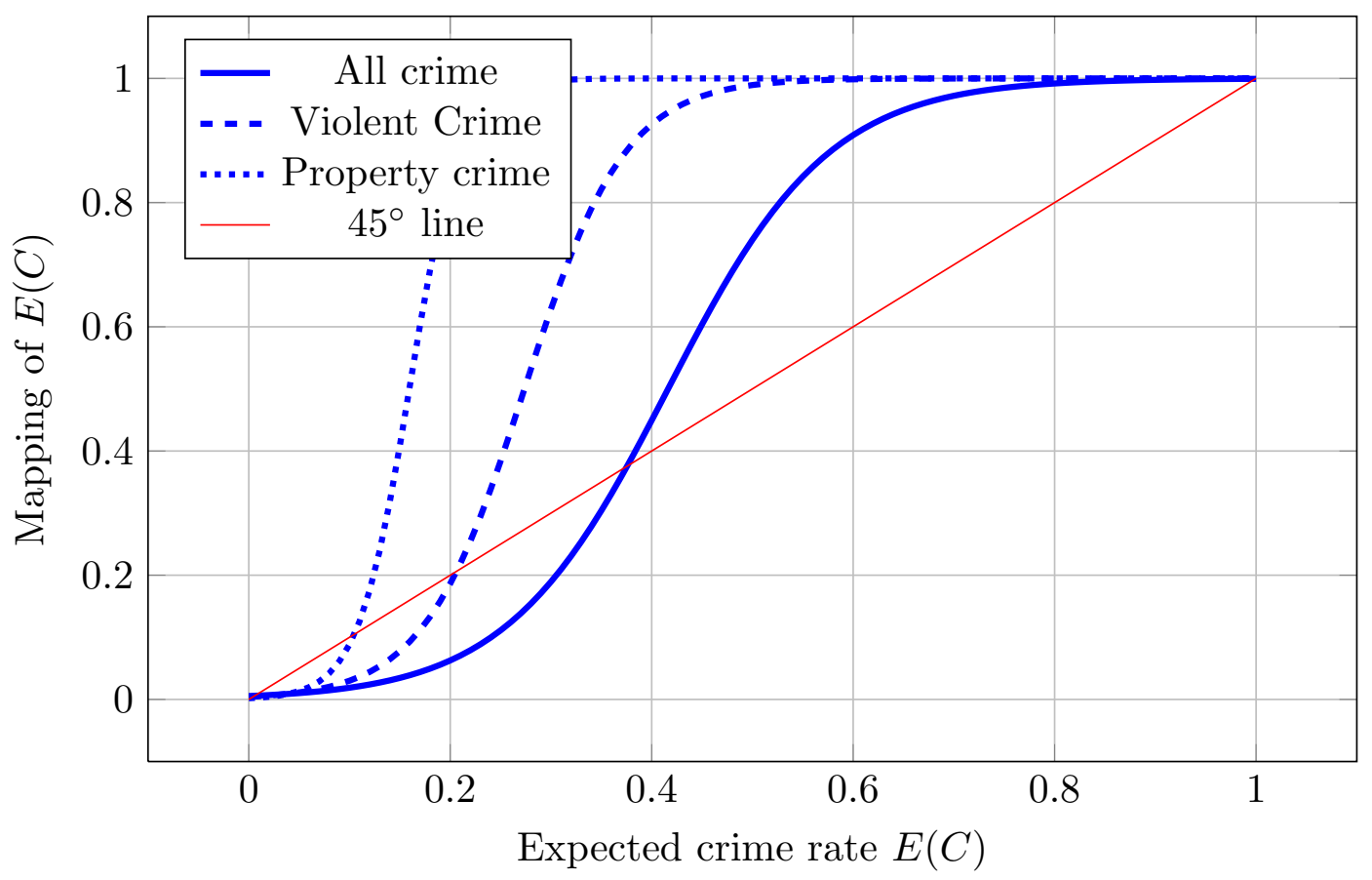

Figure 7 - Possible equilibria for multiple forms of crime based on parameter estimates for the total sample and city-average exogeneous variables (with maximum offender rates for all crime, violent crime and property crime being 16.8, 15.7, 16.0 respectively)

Figures 7 and 8 show the equilibria for our total sample and the youth only implied by the models that use municipality average covariates. Now the attraction basins of the low share equilibria are much smaller. Indeed, the unstable equilibra that indicates the upper bound of this basin is within the range of some of our observations, most notably for a few neighborhoods with respect to property crime. ${ }^{12}$ Although this may be interpreted as suggesting that some Dutch neighborhoods may run the risk of switching towards a

\footnotetext{
${ }^{12}$ Not surprisingly, the distribution of neighborhood offender rates is highly skewed to the right. 90 percent of all neighborhoods (for all crime) to more than 95 percent (for property crime) display offender rates below 5 percent. Depending on type of crime, less than 5 neighborhoods display offender rates above 10 percent.
} 


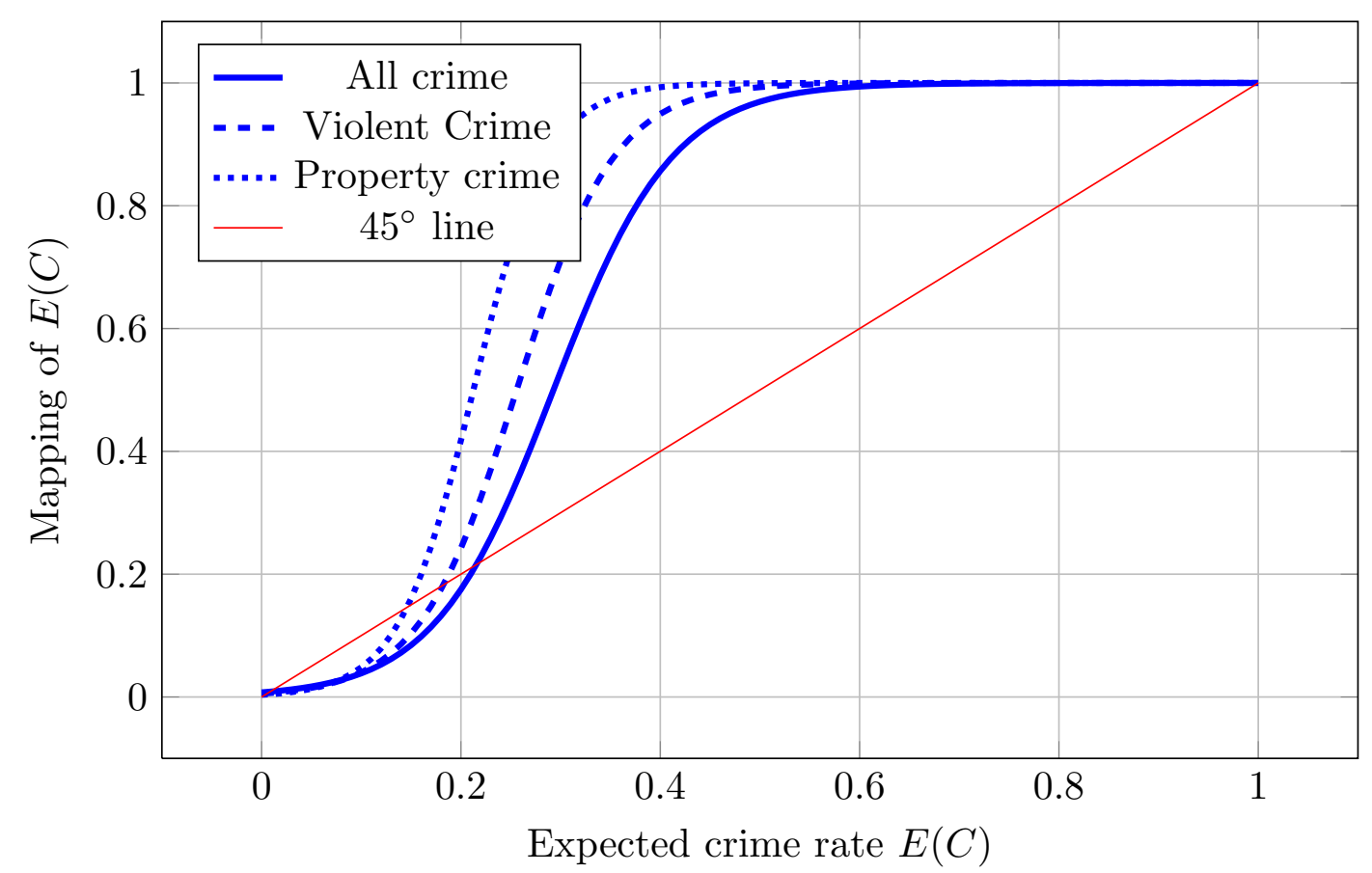

Figure 8 - Possible equilibria for multiple forms of crime based on parameter estimates for the youth and city-average exogeneous variables (with maximum offender rates for all crime, violent crime and property crime being 18.9, 15.7, 11.6 respectively)

much higher level of criminality we do not observe such high offender rates in the data for any of the Dutch neighborhoods. We interpret this as indicating that - at least in the present circumstances - the lower level equilibrium is the only relevant one.

The 'social multiplier' of criminal behavior implied by our model was derived in (8). It gives the additional impact of a change in an exogenous variable on the equilibrium offender rate that is caused by the social interaction effect. Since the expression $E\left(C_{j}\right)\left(1-E\left(C_{j}\right)\right)$ reaches a maximum value of 0.25 for $E\left(C_{j}\right)=0.5$, whereas the offender rates we observe are in general much lower, and our estimates of the field effect $\gamma$ are well below 1, we should not expect large values of this multiplier. Computations reveal that for the model referring to the youth only, with municipality averages of the demographic variables (column (VIII) of Table 2) this multiplier reaches values in the range 1.015-1.025 (for neighborhoods with high offender rates, $E\left(C_{j}\right)=0.1$ ), which is indeed small. 


\section{Discussion}

On the basis of previous literature it was hypothesized that positive social interactions play a role in crime, in particular in violent crime. Using data on individual choices and taking unobserved neighborhood characteristics and sorting into account, our analysis of offender rates confirms this expectation. They indicate a positive and significant endogenous social interaction effect for crime overall, as well as for violent crime and property crime considered separately. However, our models do not suggest that multiple equilibria are relevant in the present Dutch circumstances. Nor do they imply important social multiplier effects of criminal behavior. This contrasts with some earlier research on social interactions and crime Glaeser et al. (1996). We suggest that prior research may have overestimated endogenous social interaction effects by lack of individual data at a detailed spatial scale. In particular, we demonstrated that there exist huge individual differences in crime involvement by sex, age and ethnic background, which have hardly been accounted for in prior research on social endogenous interactions and crime.

Nevertheless, we did find positive social interaction effects in all three models once endogeneity and sorting effects were taken into account. This is in line with much of the prior literature. The result for violent crime is easiest to interpret. Apart from violent crime's reciprocal nature, another interpretation might be that social interactions apply to violent crime because violent crimes are overt predatory contact crimes that presume an interaction between the offenders and their victims. In neighborhoods where individuals live amongst others who are prone to violence, the risk of violent victimization is relatively high and might be lowered by gaining a reputation of 'toughness'. Thus, being a violent offender may deter violent predators and thereby prevent future violent victimization (Dur and Weele, 2012; Fagan and Meares, 2008; Silverman, 2004). The larger coefficient for the social interaction effect related to property crime is perhaps a bit more difficult to interpret. Although the large majority of property crimes (larceny, 
burglary, etc.) are covert crimes that are perpetrated without any contact between the perpetrator and the victim, and without the victim being able to identify the perpetrator (and often also vice versa), it also covers crimes that have a social component. For instance, shoplifting and vandalism (including graffiti-making) may give the delinquent a reputation in his (or perhaps her) peer group that evokes similar behavior by others.

As we have pointed out earlier in this paper, there are some advantages as well as disadvantages of using police-recorded data on criminal behavior. First, some crimes are not reported to the police (more than 50 percent according to conservative estimates Goudriaan et al. (2004)), and, second, the police solves only 20 percent of the recorded crimes (Dodd et al., 2004). Police data thus suffer from both type I and type II errors (although, as we have argued, the likelihood of a 'false positive' is quite small). In future research, such misclassification issues might be dealt with. Lewbel (2000) has shown that binary discrete choice models with misclassification are non-parametrically identified and Hausman et al. (1989) provide techniques for estimating this model.

A second issue that could be further addressed in subsequent research is that we found the share of single parent households to be an extremely important variable. We were, however, unable to test the hypothesis suggested by this finding, viz. that criminals often belong to such households since our data only inform us about the share of one-parent households per neighborhood. With better data, this issue could be addressed.

In a critique of the empirical literature on social interactions, Manski (2000) claims that the analysis would benefit from the performance of well-designed experiments in controlled environments and from careful elicitation of persons' subjective perceptions of the interactions in which they participate. Falk et al. (2010) adopt the first suggestion and demonstrate social interactions in an experiment on behavior in a public goods game. However, ethical considerations and Institutional Research Board regulations prohibit experimental studies of criminal behavior of the type and severity that we study. 
Therefore, in the present paper we chose the second-best alternative, and estimated a structural discrete model using state-of-the-art techniques to tease out social interactions with an exceptionally rich and comprehensive dataset. Our results confirm the presence of social interaction effects, but according to our estimates they are not strong enough to make the presence of multiple equilibria in Dutch neighborhoods likely. The implied social multiplier is small, almost negligible. The bottom line of our findings therefore is that in our data the variation in exogenous determinants of crime, like the demographic composition of the area and personal characteristics, appear to be more relevant for the explanation of geographical differences in offender rates than social interactions. 


\section{References}

Akers, R. L. (1985). Deviant Behavior: A Social Learning Approach. Belmont: California Wadsworth Publishing Company (cit. on p. 6).

Ballester, C., Y. Zenou, and A. Calvó-Armengol (2010). "Delinquent Networks". In: Journal of the European Economic Association 8.1, pp. 34-61 (cit. on p. 3).

Bayer, P, R McMillan, and K Rueben (2004). "An Equilibrium Sorting Model of Sorting in an Urban Housing Market". NBER, working paper no. 10865, Cambridge MA. (cit. on pp. 12, 13).

Bayer, P. and C. Timmins (2007). "Estimating Equilibrium Models Of Sorting Across Locations". In: The Economic Journal 117.518, pp. 353-374 (cit. on pp. 5, 13).

Becker, G. S. (1968). "Crime and Punishment: An Economic Approach". In: The Journal of Political Economy 76.2, pp. 169-217 (cit. on p. 3).

Beirne, P. (1987). "Adolphe Quetelet and the Origins of Positivist Criminology". In: The American Journal of Sociology 92.5, pp. 1140-1169 (cit. on p. 3).

Bernasco, W. and T. Kooistra (2010). "Effects of Residential History on Commercial Robbers' Crime Location Choices". In: European Journal of Criminology 7.4, pp. 251265 (cit. on p. 19).

Berry, S (1994). "Estimating discrete choice-models of product differentation". In: RAND Journal of Economics 25, pp. 242-262 (cit. on p. 10).

Berry, S., J. Levinsohn, and A. Pakes (1995). "Automobile prices in market equilibrium". In: Econometrica: Journal of the Econometric Society, pp. 841-890 (cit. on pp. 5, 9, 10).

Bertrand, M., E. F. Luttmer, and S. Mullainathan (2000). "Network effects and welfare cultures". In: The Quarterly Journal of Economics 115.3, pp. 1019-1055 (cit. on pp. 5, 30).

Blokland, A. A. J., D. S. Nagin, and P Nieuwbeerta (2005). "Life span offending trajectories of a dutch conviction cohort". In: Criminology 43.4, pp. 919-954 (cit. on p. 19).

Blom, M et al. (2005). Verdacht van criminaliteit: Allochtonen en autochtonen nader bekeken [Suspected of crimet: Non-natives and natives examined more closely]. Heerlen/Den Haag: CBS/WODC (cit. on p. 16).

Brock, W. A. and S. N. Durlauf (2001). "Discrete choice with social interactions". In: The Review of Economic Studies 68.2, pp. 235-260 (cit. on pp. 5, 10, 11, 14).

Bursik Jr., R. J. and H. G. Grasmick (1993). Neighborhoods and Crime: The Dimensions of Effective Community Control. New York: Lexington Books (cit. on p. 22).

Calvo-Armengol, A. and Y. Zenou (2004). "Social networks and crime decisions: The rols of social structure in facilitating delinquent behavior". In: International Economic Review 45.3, p. 20 (cit. on p. 3).

Case, A. C. and L. F. Katz (1991). "The Company You Keep: The Effects of Family and Neighborhood on Disadvantaged Youth ". NBER working paper 3705 (cit. on p. 3).

Dodd, T et al. (2004). "Crime in England and Wales 2003/2004." Home Office Statistical Bulletin No.10/04. London: Home Office (cit. on pp. 17, 35). 
Dur, R. and J. van der Weele (2012). "Status-Seeking in Criminal Subcultures and the Double Dividend of Zero-Tolerance". In: Journal of Public Economic Theory forthcomin (cit. on p. 34).

Elliott, D. S., D. Huizinga, and S. S. Ageton (1985). Explaining Delinquency and Drug Use. Beverly Hills, CA: Sage (cit. on p. 15).

Evans, W. N., W. E. Oates, and R. M. Schwab (1992). "Measuring peer group effects: A study of teenage behavior". In: Journal of Political Economy, pp. 966-991 (cit. on pp. 23, 29).

Fagan, J. and T. L. Meares (2008). "Punishment, Deterrence and Social Control: The Paradox of Punishment in Minority Communities". In: Ohio State Journal of Criminal Law 6, pp. 173-229 (cit. on p. 34).

Falk, A., U. Fischbacher, and S. Gächter (2010). "Living in Two Neighborhoods: Social Interaction Effects in the Laboratory". In: Economic Inquiry (cit. on p. 35).

Farrington, D. P. et al. (1996). "Self-reported delinquency and a combined delinquency seriousness scale based on boys, mothers, and teachers: Concurrent and predictive validity for African-Americans and Caucasians". In: Criminology 34.4, pp. 493-517 (cit. on p. 15).

Festinger, L, S Schachter, and K Back (1950). Social Pressures in Informal Groups: A Study of Human Factors in Housing. New York: Harper (cit. on p. 7).

Freeman, S, J Grogger, and J Sonstelie (1996). "The Spatial Concentration of Crime". In: Journal of Urban Economics 40.2, pp. 216-231 (cit. on p. 3).

Friendly, M. (2007). “A.-M. Guerry's Moral Statistics of France: Challenges for Multivariable Spatial Analysis". In: Statistical Science 22, pp. 368-399 (cit. on p. 3).

Glaeser, E. L. and B. Sacerdote (1999). "Why is There More Crime in Cities". In: Journal of Political Economy 107.S6, pp. 225-258 (cit. on pp. 22, 23, 28).

Glaeser, E. L., B. Sacerdote, and J. A. Scheinkman (1996). "Crime and Social Interactions". In: The Quarterly Journal of Economics 111.2, pp. 507-548 (cit. on pp. 3-5, 34).

Gottfredson, M. R. and T Hirschi (1990). A general theory of crime. Palo Alto: Stanford University Press (cit. on p. 6).

Goudriaan, H, J. P. Lynch, and P Nieuwbeerta (2004). "Reporting to the police in Western nations: A theoretical analysis of the effects of social context". In: Justice Quarterly 21.4, pp. 933-969 (cit. on pp. 16, 35).

Hagestad, G. O. and P. Uhlenberg (2006). "Should we be concerned about age segregation? Some theoretical and empirical explorations". In: Research on Aging 28.6, pp. 638-653 (cit. on pp. 4, 28).

Hausman, J. A., J Abrevaya, and F. M. Scott-Morton (1989). "Misclassification of the dependent variable in a discrete-response setting". In: Journal of Econometrics 87, pp. 239-269 (cit. on p. 35).

Lewbel, A (2000). "Identification of the binary choice model with misclassification". In: Econometric Theory 16, pp. 203-209 (cit. on p. 35).

Manski, C. F. (1988). "Identification of Binary Response Models". In: Journal of the American Statistical Association 83.403, pp. 729-738 (cit. on p. 11).

- (1993). "Identification of endogenous social effects: The reflection problem". In: The review of economic studies 60.3 , pp. 531-542 (cit. on pp. 5, 6, 11). 
Manski, C. F. (2000). "Economic analysis of social interactions". In: Journal of Economic Perspectives 14.3, pp. 115-136 (cit. on pp. 3, 35).

Mears, D. P., M Ploeger, and M Warr (1998). "Explaining the gender gap in delinquency: Peer influence and moral evaluations of behavior". In: Journal of Research in Crime and Delinquency 35.3, pp. 251-266 (cit. on p. 18).

Morselli, C and P Tremblay (2004). "Criminal achievement, offender networks and the benefits of low self-control". In: Criminology 42.3, pp. 773-804 (cit. on p. 15).

Nieuwbeerta, P et al. (2008). "Neighborhood characteristics and individual homicide risks - Effects of social cohesion, confidence in the police, and socioeconomic disadvantage". In: Homicide Studies 12.1, pp. 90-116 (cit. on p. 19).

Patacchini, E. and Y. Zenou (2012). "Juvenile Delinquency and Conformism". In: Journal of Law, Economics, and Organization 28.1, pp. 1-31 (cit. on p. 7).

Sampson, R. J., S. W. Raudenbush, and F Earls (1997). "Neighborhoods and violent crime: A multilevel study of collective efficacy". In: Science 277.5328, pp. 918-924 (cit. on p. 22).

Sampson, R. J. and W. B. Groves (1989). "Community Structure and Crime: Testing Social Disorganization Theory". In: American Journal of Sociology 94, pp. 773-802 (cit. on p. 22).

Sampson, R. J., T. Gannon-Rowley, and J. D. Morenoff (2002). "Assessing "Neighbourhood Effects": Social Processes and New Directions in Research". In: Annual Review of Sociology 28, pp. 443-78 (cit. on p. 8).

Silverman, D. (2004). "Street Crime and Street Culture". In: International Economic Review 45.3, pp. $761-786$ (cit. on p. 34).

Steffensmeier, D and E Allan (1996). "Gender and crime: Toward a gendered theory of female offending". In: Annual review of sociology 22, pp. 459-487 (cit. on p. 18).

Sutherland, E. H. (1947). Principles of criminology. Chicago: University of Chicago Press (cit. on p. 6).

Sykes, G. M. and D Matza (1957). "Techniques of Neutralization - A Theory of Delinquency". In: American sociological review 22.6, pp. 664-670 (cit. on p. 6).

Walker, J. L. et al. (2011). "Correcting for endogeneity in behavioral choice models with social influence variables". In: Transportation Research Part A-Policy and Practice 45.4 , pp. 362-374 (cit. on pp. 9, 10, 12, 19).

Weerman, F. M. (2011). "Delinquent Peers in Context: A Longitudinal Network Analysis of Selection and Influence Effects". In: Criminology 49.1, pp. 253-286 (cit. on p. 7).

Wikström, P.-O. H. et al. (2012). Breaking Rules: The Social and Situational Dynamics of Young People's Urban Crime. Oxford: Oxford University Press (cit. on p. 15).

Wilsem, J. van, K. Wittebrood, and N. D. de Graaf (2006). "Socioeconomic Dynamics of Neighborhoods and the Risk of Crime Victimization: A Multilevel Study of Improving, Declining, and Stable Areas in the Netherlands". In: Social Problems 53, pp. 226-247 (cit. on p. 19).

Zenou, Y. (2003). "The Spatial Aspects of Crime". In: Journal of the European Economic Association 1.2-3, pp. 459-467 (cit. on p. 3). 


\section{A. Background tables}

Table 3 - Number of criminal suspects in 2006 per 1,000 individuals, by age, sex and ethnic origin.

\begin{tabular}{|c|c|c|c|c|c|c|c|c|c|}
\hline \multirow[b]{2}{*}{ Age } & \multicolumn{3}{|c|}{ Male } & \multicolumn{3}{|c|}{ Female } & \multicolumn{3}{|c|}{ Total male and female } \\
\hline & Native & Foreign & $\begin{array}{l}\text { Total } \\
\text { male }\end{array}$ & Native & Foreign & $\begin{array}{l}\text { Total } \\
\text { female }\end{array}$ & $\begin{array}{l}\text { Total } \\
\text { native }\end{array}$ & $\begin{array}{l}\text { Total } \\
\text { foreign }\end{array}$ & $\begin{array}{c}\text { Grand } \\
\text { total }\end{array}$ \\
\hline $10-14$ & 0.71 & 2.73 & 1.02 & 0.25 & 0.72 & 0.32 & 0.48 & 1.75 & 0.68 \\
\hline $15-19$ & 4.95 & 13.46 & 6.27 & 1.07 & 2.63 & 1.31 & 3.05 & 8.20 & 3.84 \\
\hline $20-24$ & 5.15 & 11.55 & 6.21 & 0.86 & 2.07 & 1.06 & 3.03 & 6.80 & 3.67 \\
\hline $25-29$ & 3.27 & 8.98 & 4.17 & 0.63 & 1.52 & 0.78 & 1.96 & 5.12 & 2.47 \\
\hline $30-34$ & 2.52 & 7.62 & 3.23 & 0.51 & 1.37 & 0.64 & 1.52 & 4.40 & 1.94 \\
\hline $35-39$ & 2.31 & 6.49 & 2.82 & 0.54 & 1.41 & 0.64 & 1.43 & 4.00 & 1.74 \\
\hline $40-44$ & 2.09 & 5.80 & 2.50 & 0.52 & 1.18 & 0.59 & 1.31 & 3.61 & 1.56 \\
\hline $45-49$ & 1.72 & 5.16 & 2.02 & 0.44 & 1.11 & 0.50 & 1.08 & 3.18 & 1.27 \\
\hline 50-54 & 1.36 & 4.04 & 1.53 & 0.32 & 0.83 & 0.36 & 0.84 & 2.41 & 0.95 \\
\hline $55-59$ & 1.05 & 2.57 & 1.13 & 0.24 & 0.52 & 0.26 & 0.65 & 1.54 & 0.70 \\
\hline $60-64$ & 0.81 & 1.86 & 0.86 & 0.19 & 0.29 & 0.19 & 0.50 & 1.13 & 0.53 \\
\hline $65-69$ & 0.60 & 1.04 & 0.62 & 0.12 & 0.20 & 0.12 & 0.35 & 0.67 & 0.36 \\
\hline $70-74$ & 0.40 & 0.78 & 0.41 & 0.08 & 0.27 & 0.09 & 0.23 & 0.53 & 0.24 \\
\hline $75-79$ & 0.28 & 0.65 & 0.28 & 0.07 & 0.25 & 0.07 & 0.15 & 0.42 & 0.16 \\
\hline $80-84$ & 0.20 & 0.43 & 0.20 & 0.04 & 0.00 & 0.04 & 0.09 & 0.15 & 0.10 \\
\hline $85-89$ & 0.18 & 0.27 & 0.18 & 0.02 & 0.00 & 0.02 & 0.07 & 0.08 & 0.07 \\
\hline Total & 1.99 & 7.00 & 2.49 & 0.41 & 1.36 & 0.50 & 1.19 & 4.21 & 1.49 \\
\hline
\end{tabular}

Source: Statistics Netherlands and Netherlands National Police Services (KLPD) 
Table 4 - First stage of 2SLS regression on Offender rate and Offender rate $\times$ density

\begin{tabular}{|c|c|c|}
\hline & Offender rate & $\begin{array}{l}\text { Offender rate } \times \\
\text { (address density) }\end{array}$ \\
\hline Instrument $\left(I E\left(C_{j}\right)\right)$ & $\begin{array}{l}85.857 * * \\
(4.528)\end{array}$ & $\begin{array}{c}-3.357 * \\
(1.510)\end{array}$ \\
\hline Instrument interaction effect & $\begin{array}{l}10.198 \\
(6.418)\end{array}$ & $\begin{array}{l}97.450 * * \\
(2.140)\end{array}$ \\
\hline Address density $\div 100$ & $\begin{array}{r}-0.007 \\
(0.162)\end{array}$ & $\begin{array}{l}0.276 * * \\
(0.054)\end{array}$ \\
\hline $\begin{array}{l}\text { Number of elementary schools } \\
\text { per } 10000 \text { inhabitants }\end{array}$ & $\begin{array}{r}-0.004 \\
(0.002)\end{array}$ & $\begin{array}{c}-0.001 \\
(0.001)\end{array}$ \\
\hline $\begin{array}{l}\text { Number of shops in each } \\
\text { neighborhood } \div 100\end{array}$ & $\begin{array}{r}-0.007 \\
(0.008)\end{array}$ & $\begin{array}{c}0.003 \\
(0.003)\end{array}$ \\
\hline One person households & $\begin{array}{c}0.396+ \\
(0.207)\end{array}$ & $\begin{array}{l}0.126+ \\
(0.069)\end{array}$ \\
\hline One parent households & $\begin{array}{c}0.389 \\
(0.698)\end{array}$ & $\begin{array}{c}0.424+ \\
(0.233)\end{array}$ \\
\hline Persons per household & $\begin{array}{r}-0.068 \\
(0.077)\end{array}$ & $\begin{array}{r}-0.031 \\
(0.026)\end{array}$ \\
\hline Average education & $\begin{array}{l}-0.201 * * \\
(0.042)\end{array}$ & $\begin{array}{c}-0.067 * * \\
(0.014)\end{array}$ \\
\hline Social class & $\begin{array}{r}-0.001 \\
(0.024)\end{array}$ & $\begin{array}{l}0.022 * * \\
(0.008)\end{array}$ \\
\hline Two earner households & $\begin{array}{c}0.022 \\
(0.016)\end{array}$ & $\begin{array}{l}0.025 * * \\
(0.005)\end{array}$ \\
\hline Rate of out-migration & $\begin{array}{r}-0.001 \\
(0.002)\end{array}$ & $\begin{array}{r}-0.001 * \\
(0.001)\end{array}$ \\
\hline Rate of in-migration & $\begin{array}{c}0.000 \\
(0.002)\end{array}$ & $\begin{array}{c}0.001 \\
(0.001)\end{array}$ \\
\hline Percentage homeowners $\div 100$ & $\begin{array}{l}0.261 * * \\
(0.095)\end{array}$ & $\begin{array}{l}0.149 * * \\
(0.032)\end{array}$ \\
\hline Police availability & $\begin{array}{c}0.013+ \\
(0.007)\end{array}$ & $\begin{array}{c}0.004+ \\
(0.002)\end{array}$ \\
\hline Constant & $\begin{array}{c}0.354 \\
(0.244)\end{array}$ & $\begin{array}{r}-0.103 \\
(0.081)\end{array}$ \\
\hline Observations & 3210 & 3210 \\
\hline$R^{2}$ & 0.661 & 0.919 \\
\hline $\mathrm{F}$ & 414.924 & 2416.900 \\
\hline
\end{tabular}

Standard errors in parentheses

Statistical significance levels: $+p<0.1,{ }^{*} p<0.05,{ }^{* *} p<0.01$ 


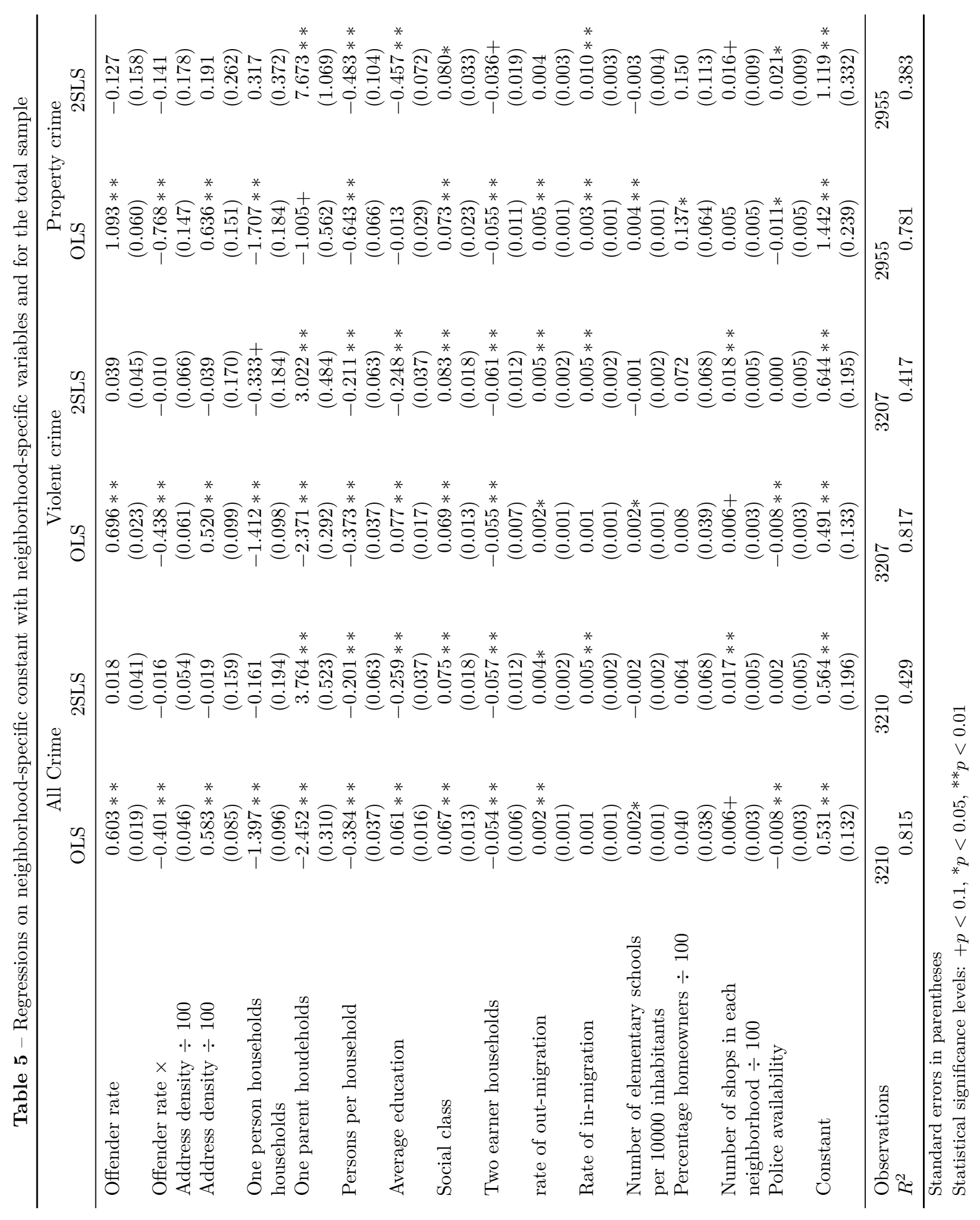

